\title{
Binary social group optimization algorithm for solving 0-1 knapsack problem
}

\author{
Anima Naik ${ }^{a^{*}}$ and Pradeep Kumar Chokkalingam ${ }^{\mathrm{b}}$
}

${ }^{a}$ Department of CSE, KL University, Hyderabad, Telangana, India

${ }^{b}$ Department of IS, HPCL, Mumbai, Maharashtra, India

\section{H R O N I C L E}

Article history:

Received May 5, 2021

Received in revised format:

June 1, 2021

Accepted August 182021

Available online

August 19, 2021

Keywords:

Combinatorial optimization

problem

Meta-heuristic algorithms

0-1 knapsack

Binary algorithm

Performance

\begin{abstract}
A B S T R A C T
In this paper, we propose the binary version of the Social Group Optimization (BSGO) algorithm for solving the 0-1 knapsack problem. The standard Social Group Optimization (SGO) is used for continuous optimization problems. So a transformation function is used to convert the continuous values generated from SGO into binary ones. The experiments are carried out using both low-dimensional and high-dimensional knapsack problems. The results obtained by the BSGO algorithm are compared with other binary optimization algorithms. Experimental results reveal the superiority of the BSGO algorithm in achieving a high quality of solutions over different algorithms and prove that it is one of the best finding algorithms especially in highdimensional cases.
\end{abstract}

(C) 2022 by the authors; licensee Growing Science, Canada.

\section{Introduction}

The 0-1 knapsack problem (KP) may be defined mathematically as,

$$
\begin{aligned}
& \min \sum_{i=\mathbf{1}}^{N} \boldsymbol{p}_{\boldsymbol{i}} \boldsymbol{x}_{\boldsymbol{i}} \\
& \text { subject to } \\
& \sum_{\boldsymbol{i}=\mathbf{1}}^{N} \boldsymbol{w}_{\boldsymbol{i}} \boldsymbol{x}_{\boldsymbol{i}} \leq \boldsymbol{C}, \quad \boldsymbol{x}_{\boldsymbol{i}} \in\{\mathbf{0}, \mathbf{1}\}
\end{aligned}
$$

where $N$ is the set of items are contained by KP, each item has a weight $w_{i}$ and a profit $p_{i}$. $\mathrm{C}$ is the maximum weight capacity of knapsack and $x_{i}$ is the number of copies of item $\mathrm{i}$ is presented in the knapsack. The $0-1 \mathrm{KP}$ is an NP-hard combinatorial optimization problem. There are several methods to solve the knapsack problems and are categorized into exact algorithms and meta-heuristic algorithms. Exact algorithms such as dynamic programming and branch-and-bound can give accurate solutions. But the worst case occurs when the problem size increase. When the size of the problem increases, then the computation time increases exponentially. The meta-heuristic algorithms can give approximate solutions at reasonable times compared to exact algorithms (Martello et al., 2000). From a few decades, meta-heuristic algorithms play significant roles in solving optimization problems that imitate natural phenomena. The meta-heuristic algorithms in avoiding local optimal solutions generate multiple solutions at each run, which help to produce optimal global solutions quickly without the needs of gradient methods. Extensive works have been carried out based on meta-heuristic algorithms in recent decades to solve 01 KP. A modified version of ant colony optimization (ACO) is proposed to solve 0-1 KP (Shi, 2006). Particle swarm optimization (PSO) is applied to solve multidimensional KP (Kong \& Tian, 2006). Improved hybrid adaptive genetic algorithm (IHAGA) (Ma \& Wan, 2011) is applied to solve KP. A novel global harmony search algorithm (Zou et al., 2011), a hybrid quantum-inspired harmony search algorithm (Layeb, 2013) is applied to solve 0-1 KPs. An artificial glow-worm

* Corresponding author.

E-mail address: animanaik@klh.edu.in (A. Naik)

(C) 2022 by the authors; licensee Growing Science, Canada.

doi: $10.5267 /$ j.dsl.2021.8.004 
swarm optimization algorithm is applied for solving 0-1 KP (Gong et al., 2011). A novel quantum-inspired cuckoo search (Layeb, 2011), discrete binary version of the cuckoo search algorithm (Gherboudj, Layeb \& Chikhi, 2012) and, an improved hybrid encoding cuckoo search algorithm (Feng, Jia \& He, 2014) are proposed to solve 0-1 knapsack problems. A modified binary PSO algorithm is proposed to solve KP (Bansal \& Deep, 2012). The amoeboid organism algorithm is applied to 0-1 KP (Zhang et al., 2013). Shuffled frog leaping algorithm is also applied to solve 0-1 KP (Bhattacharjee \& Sarmah, 2014). An ant colony optimization algorithm is applied to solve KP (Changdar \& Mahapatra, 2013). Chemical reaction optimization based on a greedy strategy (CROG) (Truong et al., 2015) is proposed to solve 0-1 KP. A simplified binary harmony search algorithm is proposed for large scale 0-1 knapsack problems (Kong et al., 2015). A hybrid algorithm based on tabu search and chemical reaction optimization is proposed to solve 0-1 KP (Yan et al., 2015). Greedy strategy based self-adaption ant colony algorithm is introduced for the 0-1 knapsack problem ( $\mathrm{Du} \& \mathrm{Zu}, 2015)$. In addition, many algorithms have been prospered for solving 0-1 KP such as Cognitive discrete gravitational search algorithm(CDGSA) (Razavi \& Sajedi, 2015), wind driven Optimization(WDO) (Zhou et al., 2017), greedy degree and expectation efficiency (Lv et al., 2016), improved monkey algorithm (IMA) (Zhou et al., 2016a), monogamous pairs genetic algorithm (MPGA) (Lim et al., 2016), hybrid greedy and particle swarm (GPSO) (Nguyen, Wang \& Truong, 2016), Quantum inspired social evolution (QSE) algorithm (Pavithr, 2016), binary particle swarm optimization based on the surrogate information with proportional acceleration coefficients (Lin et al., 2016), complex-valued encoding bat algorithm (Zhou et al., 2016b), cohort intelligence (CI) algorithm (Kulkarni et al., 2017), Migrating birds optimization (MBO) algorithm (Ulker \& Tongur, 2017), binary flower pollination algorithm (BFPA) (Abdel-Basset et al., 2018a), binary bat algorithm (BBA) (Rizk-Allah et al., 2018), Social-Spider Optimization(SSO) Algorithm [Zhao et al., 2018; Nguyen et al., 2017), binary monarch butterfly optimization(BMBO) (Feng et al., 2016a), Binary Dragonfly Algorithm(BDA) (Abdel-Basset at al., 2017), Binary Fisherman Search (BFS) algorithm (Cobos et al., 2016), elite opposition-flower pollination algorithm (EOFPA) (Abdel-Basset et al., 2018b), Opposition-based learning monarch butterfly optimization with Gaussian perturbation(OLMBO) (Feng et al., 2017). In respect of the importance of knapsack problem in practical applications, developing new algorithms to solve large-scale types of knapsack problem applications undoubtedly becomes a true challenge.

Social Group Optimization (SGO) algorithm is one of the new Metaheuristics algorithms that is inspired by the social behavior of a human to solve a complex problem (Satapathy \& Naik, 2016; Naik et al., 2018). The SGO algorithm has solved different optimization problems and proved its efficiency and robustness compared to different algorithms. After that, many researchers have explored this optimization technique for solving various complex problems in different research areas. In the medical field, social group optimization supported as an automated tool to examine skin melanoma in dermoscopy images (Dey et al., 2019). SGO with Fuzzy-Tsallis entropy helps in the segmentation of ischemic stroke lesion in brain MRI (Rajinikanth \& Satapathy, 2018). In the field of electrical science, a transformer fault diagnosis model is introduced using an optimal hybrid dissolved gas analysis features subset with improved social group optimization and support vector machine classifier (Fang et al., 2018). SGO algorithm is used to develop a procedure to maximize the natural frequencies of laminated composite stiffened panels. It optimizes the quantities and sizes of the stiffener to maximize the fundamental rate of the groups under certain constraints (Tran et al., 2017). In a cloud environment, adequate resource allocation and scheduling of tasks are proposed using SGO for minimizing the makespan time and maximizing throughput (Praveen et al., 2018). The circular array synthesis is performed using social group optimization. The synthesis technique employs both non-uniform amplitudes and non-uniform spacing between the elements (Chakravarthy et al., 2018). SGO is used to solve the optimized problem of economic load dispatch in the operational planning of the power system (Madhavi \& Harika, 2018). SGO has been used in gray and RGB image multi-level pre-processing (Monisha et al., 2019). The application of SGO can also be shown in the wireless sensor network (Parwekar, 2018). Like this, there are so many areas where SGO performs its use in solving problems (Leena et al., 2018; Pham et al., 2018; Mani et al., 2017; Catharin et al., 2018; Rani \& Suri, 2019; Naik \& Satapathy, 2021; Naik et al., 2020 ; Naik et al., 2021). But, solving combinational optimization problems using SGO have not received attention yet. Due to continuous nature of SGO, it is in its infancy for solving combinatorial optimization problems, so this is the motivation behind this study. Also solving large-scale knapsack problems have not received adequate attention yet, so this can be another motivation. Solving large-scale knapsack problems to optimality undoubtedly becomes a true challenge. Therefore, in this paper we propose a novel binary social group optimization (BSGO) algorithm to solve 0 -1 knapsack problems. First, the proposed algorithm is tested on different size instances KPs from the literature, after that the proposed algorithm is effectively applied for large-size problems. The experimental results demonstrated the superiority of the proposed algorithm in achieving a high quality of solutions

The rest of the paper is arranged as follows. Section 2 gives a brief description of the SGO algorithm. The proposed BSGO algorithm is explained in detail in Section.3. Simulation and experimental results are presented in Sect. 4. Finally, section 5 gives conclusions and future work.

\section{Social group optimization(SGO)}

The Social Group Optimization algorithm is a meta-heuristic population-based optimization algorithm inspired by the social behavior of humans while solving complex problems. Each person has their response and action to address the complex problems efficiently in life based on their traits and skills. Thus, group solving ability is more operative compared to individual expertise in exploring and manipulating individuals' characters in the group to solve a specific problem. Based on this concept, 
the SGO optimization technique is developed. For a detailed description of the SGO algorithm, anyone can follow the paper (Satapathy \& Naik, 2016; Naik et al., 2018).

In the SGO algorithm, the definitions and concepts are considered as follows:

a) Each person represents a candidate solution empowered with some information that has an ability level to solve a problem.

b) The information (knowledge) is affected by different traits of each person with the best person's traits influence.

c) The best person signifies the best solution.

d) The best solution is to spread knowledge amongst all persons.

e) The population is corresponding to 'fitness' that is used to improve the knowledge level of entire members in the group.

f) The SGO algorithm has two stages, namely improving and acquiring stages.

g) In the group, each person's knowledge (solution) level is improved based on the best person's influence in the improving phase.

h) The best candidate solution is the one having the highest knowledge level and ability to solve the problem under concern.

i) The mutual interaction between persons in the group through the acquiring phase is improved each person's knowledge.

The preceding definitions are applied along with the assumption that the social group contains $M$ persons and each person $P_{i}$ is defined by $P_{i}=\left(p_{i 1}, p_{i 2}, p_{i 3}, \ldots \ldots, p_{i N}\right)$, where $i=1,2,3, \ldots, M$ and $N$ refer to the allocated traits number to an individual to determine the individual's dimensions. In each social group, through the improving phase, the best candidate solution ( $g b e s t)$ tries to spread knowledge between all persons to assist others in improving their knowledge within the group. The best candidate solution at generation $g$ for solving a minimization problem is given by:

[minvalue, index $]=\min \left\{f\left(P_{i}\right), i=1,2,3, \ldots \ldots \ldots, M\right\}$

gbest $=P($ index, )

where $f$ refers to the corresponding fitness value, each candidate solution gains knowledge from the group gbest in the improving phase. Each candidate update can be intended using the following algorithm.

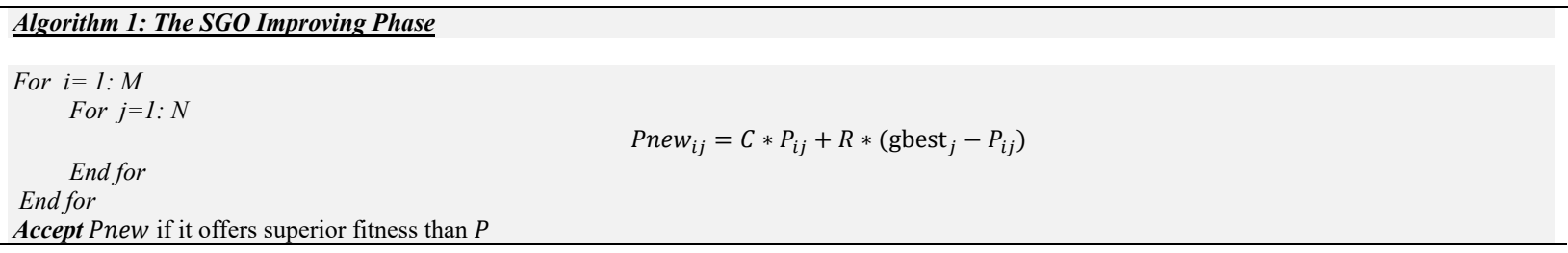

where, $C$ is the self-introspection parameter having $0<\mathrm{C}<1$, whereas $R$ is a random number specified by $R \sim U(0,1)$.

Afterward, a candidate solution of the social group interrelates with 'gbest' of that group besides its random interaction with other candidate solutions of the group to gain knowledge during the acquiring phase. A person acquires new knowledge if the other person has more knowledge. The paramount knowledgeable person having ' $g$ best' has the greatest motivation for others to learn from him/her. A person consistently will attain something new from other persons in the group, if they have more knowledge than him/her. The acquiring phase is stated as follows:

$[$ minvalue, index $]=\min \left\{f\left(P_{i}\right), i=1,2,3, \ldots \ldots \ldots, M\right\}$

gbest $=P$ (index,:)

where, $P_{i}$ 's are updated values at the end of improving phase. The acquiring stage algorithm is given as follows.

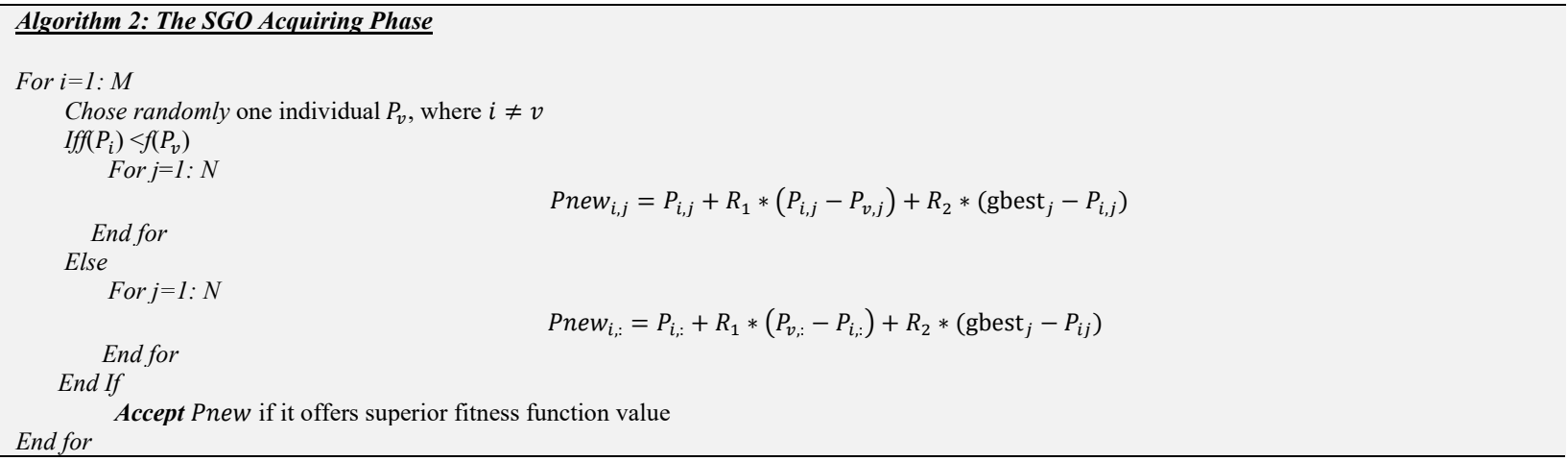


where, $R_{1}$ and $R_{2}$ are two independent random numbers, where each of them is $\sim U(0,1)$. These random numbers are used to affect the algorithm stochastic nature as exposed in the acquiring phase.

\section{Description of proposed BSGO algorithm}

The standard SGO algorithm is designed to deal with continuous problems. The knapsack problem is discrete as the problem arises in selecting or not selecting a particular item to be packed in the knapsack. One corresponds to the item being selected in the knapsack, and zero corresponds to the item being rejected out the knapsack. So to solve the $0-1$ knapsack problem using the SGO algorithm, the continuous variables have to be transformed into discrete variables. For that, the sigmoid function is adapted to make SGO deal with the knapsack problem. It takes the real values generated from the standard SGO and converts them into 1 (one) or 0(zero). The following steps will clarify the main concepts of BSGO. A framework of the BSGO algorithm is given in Fig. 1 .

\section{Initialization}

In this step, the $\mathrm{M}$ initial population of $\mathrm{N}$ dimension is generated by following algorithm 3 , where $\mathrm{N}$ is the number of available items. Each person $P_{i}$ in the population represents a solution which provides the numbers of the item available in KP.

\section{Algorithm 3: Initialization function}

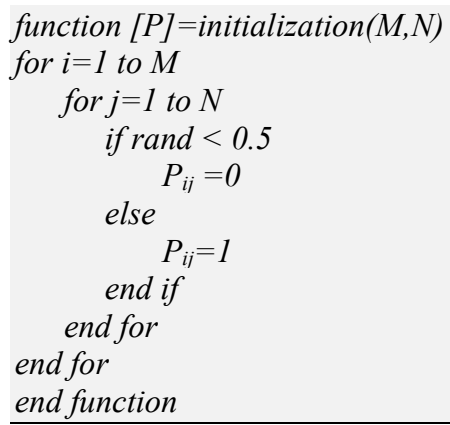

\section{Transformation}

In BSGO, a transformation function is used for mapping the real-valued solutions into binary ones using following algorithm 4. To convert real-valued to a binary one, the sigmoid function is employed.

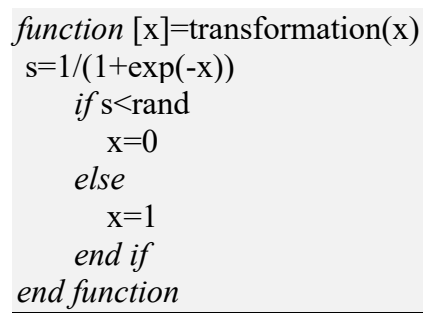

\section{Fitness calculation}

In the BSGO algorithm, the fitness function is employed for evaluating the knowledge of the person. The fitness is computed as the summation of the profits for all items selected in the knapsack. The 0-1 knapsack problem is a constrained optimization problem. So handling constrain is an integral part of calculating the fitness value of a solution because the infeasible solution may occur. In 0-1 knapsack problem, a solution will be an infeasible solution when selecting an item with maximum fitness that contradicts the constraint $\sum_{i=1}^{N} w_{i} x_{i} \leq C$. These infeasible solutions will be selected because of their maximum fitness. The fitness of a solution vector is calculated using the following algorithm 5 . Using this fitness function, we determine the fitness value (maximum profit) of the solution vector if it is feasible. If a solution vector is not feasible, then first, we make infeasible to feasible and then find fitness value. To do this, we have used a repair operator (RO) function and penalty calculation (PC) function. The repair operator is a greedy type heuristic to compute the profit per unit that is defined as:

$$
R O_{i}=\frac{P_{i}}{w_{i}}
$$


The $\mathrm{RO}$ of a solution vector is calculated using the following algorithm 6, and the PC of a solution vector is computed using algorithm 7 .

\section{Algorithm 5. Fitness function}

function $[\mathrm{x}$, fitness $]=$ fitnessfunction(x, data,capacity)

$\% \mathrm{~N}$ represents the number of items

weight=transpose $($ data(::,1));

profit=transpose (data(:,2));

ro $=$ ROfunction(x, profit, weight)

$[\mathrm{r} \mathrm{s}]=\operatorname{sort}\left(\mathrm{ro},{ }^{\prime}\right.$ ascend');

penalty $=$ PCfunction (x, weight, profit, capacity)

index $=1$;

while (penalty $<0$ \&\& index $<=\mathrm{N}$ )

$\mathrm{x}(\mathrm{s}($ index $))=0$;

index $=$ index +1 ;

penalty $=$ PCfunction( $\mathrm{x}$, weight, profit, capacity)

end while

$\mathrm{x}$;

sum $=0$;

for $\mathrm{j}=1: \mathrm{N}$

sum $=$ sum + profit $(\mathrm{j}) * \mathrm{x}(\mathrm{j})$;

end

fitness=sum;

end function

Algorithm 6. Finding RO

function [ro]=ROfunction(x, profit, weight)

$\% \mathrm{~N}$ represents the number of items

for $\mathrm{i}=1$ to $\mathrm{N}$

if $(\mathrm{x}(\mathrm{i}) \neq 0)$

ro(i)=profit(i)/weight(i);

else

ro(i) $=0$;

end if

end for

end function

\section{Algorithm 7.PC function}

function $[\mathrm{pc}]=$ PCfunction ( $\mathrm{x}$, weight, profit, capacity)

$\% \mathrm{~N}$ represents the number of items

sum $=0$;

for $\mathrm{j}=1$ to $\mathrm{N}$

sum $=$ sum + weight $(\mathrm{j}) * \mathrm{x}(\mathrm{j})$;

end for

totalweight=sum;

if (totalweight $>$ capacity)

else

$\mathrm{pc}=$ capacity-totalweight;

$\mathrm{pc}=$ totalweight;

end if 


\section{Algorithm 8: The proposed BSGO}

Define self introspection parameter C, Max_iter=Maximum iteration, $\mathrm{M}=$ =pop_size, $\mathrm{N}=$ dimension

Initialize population $\mathrm{P}$ using algorithm 3

Evaluate each person $P_{i}$ in the population using algorithm 5

Find the best solution $f^{*}$ and best person gbest

$\mathrm{t}=1$

While $(\mathrm{t}<$ Max_iter)

For each person $P_{i}$ in the population

Find new $P_{i}$ using improving phase

Transform real-valued to binary one using algorithm 4

Evaluate using algorithm 5

If new $P_{i}$ is better than $P_{i}$ then replace it and update population

\section{End for}

Find the best solution $f^{*}$ and best person gbest

For each person $P_{i}$ in the population

Find new $P_{i}$ using acquiring phase

Transform real-valued to binary one using algorithm 4

Evaluate using algorithm 5

If new $P_{i}$ is better than $P_{i}$ then replace it and update population

End for

Find the best solution $f^{*}$ and best person gbest

$\mathrm{t}=\mathrm{t}+1$

end while

return the best solution $f^{*}$

\section{Simulation and experimental result}

In this section, a comprehensive comparison study is conducted to investigate the optimization capability of the BSGO algorithm along with the convergence speed and numerical stability through two experiments. In the first experiment, 10 small-scale knapsack problems are considered. These small-scale problems are listed in Table A1 of Appendix A. In the second experiment, 30 large-scale knapsack problems are discussed. Information regarding these problems is given in Table A2 of Appendix A.

"For comparing the speed of algorithms, number of iterations or generations cannot be accepted as a time measure, since algorithms perform different amounts of works in their inner loops, and also they have different population sizes. Hence, we choose max FEs (maximum number of function evaluations) as a measure of computation time instead of generations or iterations" (Satapathy et al., 2016) Instead of generations or iterations, max_FEs have opted as a measure of computation time. Due to the stochastic nature of meta-heuristic algorithms, we have taken different independent runs (with varying seeds of random number generator) of each algorithm and found out best, mean, median, worse, and standard deviation(SD) of function values and put in tables of the experiment. For comparing the performance of algorithms, different tests are conducted on experimental results.

\subsection{Experiment 1}

In this experiment the proposed BSGO algorithm is compared with different algorithms, referred from a separate research paper. For ACO (Ant Colony Optimization), SA(Simulated Annealing, GA(Genetic Algorithm), NGHS, SSO(Social-Spider Optimization) algorithm results are reported from paper (Zhao \& Zhou, 2018). For CI (Cohort Intelligence), results are reported from (Kulkarni et al., 2017). For CWDO (complex-valued encoding wind-driven optimization) the results are considered from (Zhou et al., 2017). For IHS, the result is reported from (Zou et al., 2011). For PA (Parallel Approach based simulated annealing algorithm) the results are reported from ( Sonuc et al., 2016). For BFSP (binary fisherman search procedure), MDSFL (modified discrete shuffled frog-leaping algorithm), SBHS(simplified binary harmony search algorithm), SLC(soccer league competition algorithm) the results are reported from paper (Cobos et al., 2016). For BDA (binary dragonfly algorithm) the results are reported from (Abdel-Basset et al., 2017). For ABHS (adaptive binary harmony search (Wang et al., 2013), IBBA-RSS (injective binary bat algorithm based rough set scheme), the results are considered from their paper. The SGO algorithm is converted to binary version algorithm by using algorithm 3 and 4 of section 3 . Using algorithm 3 , the SGO algorithm is initialised, and using algorithm 4, a real-valued individual is transformed to binary ones. Using algorithm 5, the fitness value of algorithm is evaluated. For comparison of the performance of algorithms, 10 small-scale 0 1 knapsack problems are considered. For the SGO, the experiment is conducted in MATLAB 2016a on an Intel Core i5, 8 GB memory laptop in Windows 10 environment. 


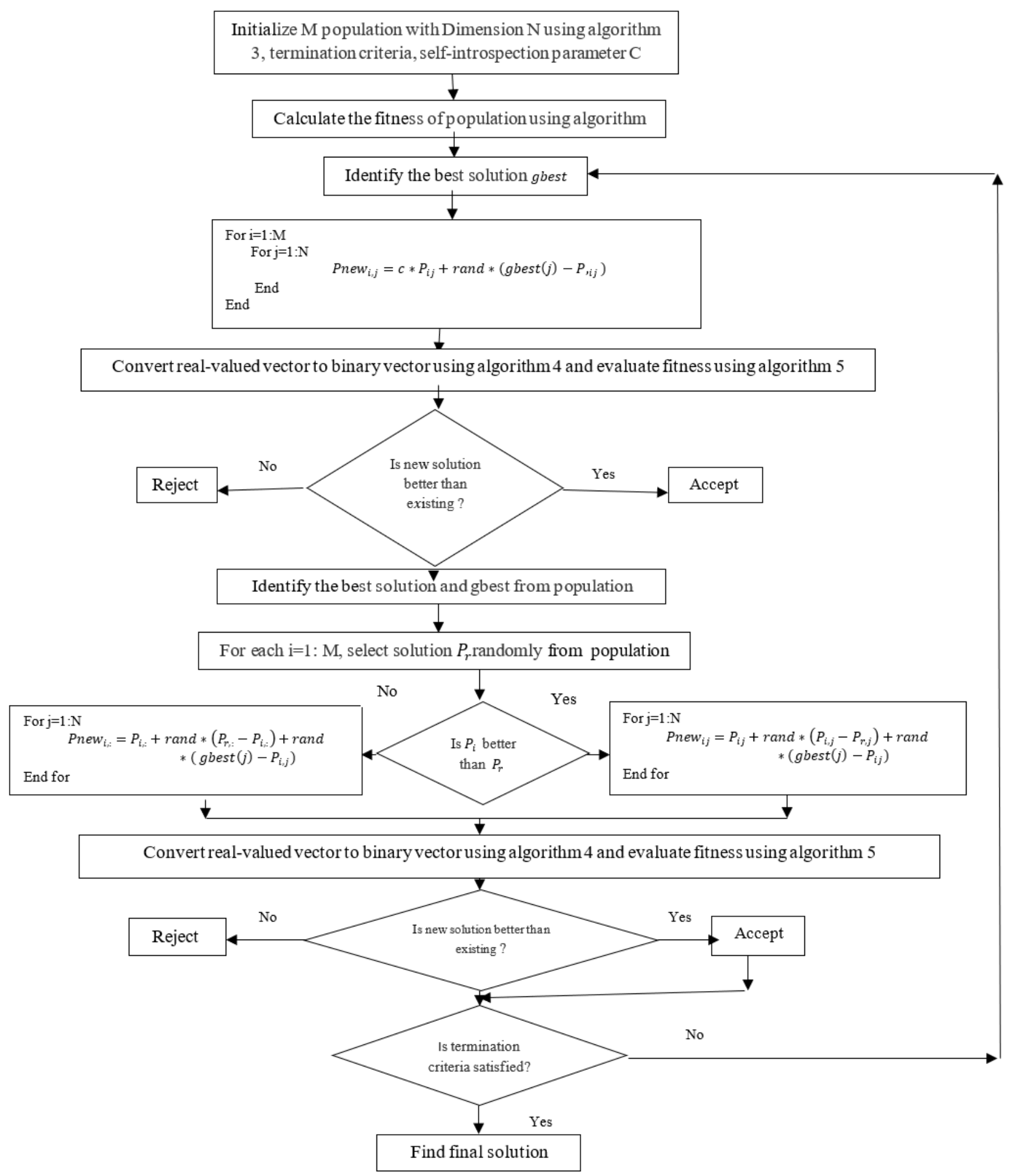

Fig. 1. Framework of BSGO algorithm

For each problem, the statistical results in terms of best value, mean value, median value, worse value and corresponding standard deviation are reported in Tables 1. The best results are highlighted in bold faces. 'NA' stands for that particular value is not available. The average error (AE) of the best profit, mean profit and worse profit for all these algorithms for all 10 0-1 $\mathrm{KP}$ is given Table 2. The AE can be defined mathematically as:

$$
\mathrm{AE}=\frac{1}{\mathrm{n}} \sum_{\mathrm{i}=1}^{\mathrm{n}} \frac{\text { profit }_{\text {opt }}-\text { prof it }_{\mathrm{i}}}{\text { profit }_{\text {opt }}} * \mathbf{1 0 0}
$$


where $n$ is the number of problems, profit $t_{\text {opt }}$ is the optimal solution for the problem, profit $t_{i}$ is the profit obtained by the algorithm for the best or mean or worse profit.

Table 1

$\underline{\text { Results of } 10 \text { low dimensional 0-1 KP problems, referred from different research paper }}$

\begin{tabular}{|c|c|c|c|c|c|c|c|c|c|c|}
\hline \multirow[t]{2}{*}{ Algorithm } & \multicolumn{5}{|c|}{$\mathrm{P} 1, \operatorname{dim}=10$, optimal value $=295$} & \multicolumn{5}{|c|}{$\mathrm{P} 2, \operatorname{dim}=20$,optimal value $=1024$} \\
\hline & Best & Median & Worse & Mean & Std & Best & Median & Worse & Mean & Std \\
\hline $\mathrm{ACO}$ & 295 & NA & 295 & 295 & 0 & 1024 & NA & 1024 & 1024 & 0 \\
\hline SA & 295 & NA & 293 & 294.8 & 0.6102 & 1024 & NA & 1024 & 1024 & 0 \\
\hline GA & 295 & NA & 295 & 295 & 0 & 1024 & NA & 1018 & 1023.8 & 1.0954 \\
\hline NGHS & 295 & 295 & 295 & 295 & 0 & 1024 & 1024 & 1024 & 1024 & 0 \\
\hline SSO & 295 & NA & 295 & 295 & 0 & 1024 & NA & 1024 & 1024 & 0 \\
\hline CWDO & 295 & NA & 295 & 295 & 0 & 1024 & NA & 1024 & 1024 & 0 \\
\hline CI & 295 & NA & 260 & 267.46 & NA & 1024 & NA & 1009 & 1020.55 & NA \\
\hline BDA & 295 & 295 & 295 & 295 & 0 & 1024 & 1024 & 1024 & 1024 & 0 \\
\hline IHS & 295 & 295 & 288 & 294.78 & 16 & 1024 & 1024 & 1024 & 1024 & 0 \\
\hline PA & 295 & 295 & 295 & 295 & 0 & 1024 & 1024 & 1024 & 1024 & 0 \\
\hline BFSP & 295 & 295 & 295 & 295 & 0 & 1024 & 1024 & 1024 & 1024 & 0 \\
\hline MDSFL & 295 & 295 & 294 & 294.66 & 0.4737 & 1024 & 1024 & 1024 & 1024 & 0 \\
\hline SBHS & 295 & 295 & 295 & 295 & 0 & 1024 & 1024 & 1018 & 1023.88 & 0.84 \\
\hline SLC & 295 & 295 & 295 & 295 & 0 & 1024 & 1024 & 1024 & 1024 & 0 \\
\hline DHS & SLC & 295 & 295 & 295 & 0 & 1024 & 1024 & 1024 & 1024 & 1024 \\
\hline ABHS & SLC & 295 & 295 & 295 & 0 & 1024 & 1024 & 1024 & 1024 & 1024 \\
\hline IBBA-RSS & SLC & 295 & 295 & 295 & 0 & 1024 & 1024 & 1024 & 1024 & 1024 \\
\hline SGO & 295 & 295 & 295 & 295 & 0 & 1024 & 1024 & 1024 & 1024 & 0 \\
\hline \multirow[t]{2}{*}{ Algorithm } & \multicolumn{5}{|c|}{$\mathrm{P} 3, \operatorname{dim}=4$, optimal value $=35$} & \multicolumn{5}{|c|}{$\mathrm{P} 4, \operatorname{dim}=4$, optimal value $=23$} \\
\hline & Best & Median & Worse & Mean & Std & Best & Median & Worse & Mean & Std \\
\hline $\mathrm{ACO}$ & 35 & NA & 35 & 35 & 0 & 23 & NA & 23 & 23 & 0 \\
\hline SA & 35 & NA & 35 & 35 & 0 & 23 & NA & 23 & 23 & 0 \\
\hline GA & 35 & NA & 35 & 35 & 0 & 23 & NA & 23 & 23 & 0 \\
\hline NGHS & 35 & 35 & 35 & 35 & 0 & 23 & 23 & 23 & 23 & 0 \\
\hline SSO & 35 & NA & 35 & 35 & 0 & 23 & NA & 23 & 23 & 0 \\
\hline CWDO & 35 & NA & 35 & 35 & 0 & 23 & NA & 23 & 23 & 0 \\
\hline CI & 35 & NA & 28 & 34.55 & NA & 23 & NA & 16 & 22.6 & 0.64 \\
\hline BDA & 35 & 35 & 35 & 35 & 0 & 23 & 23 & 23 & 23 & 0 \\
\hline IHS & 35 & 35 & 27 & 34.58 & 1.68 & 23 & 23 & 23 & 23 & 0 \\
\hline PA & 35 & 35 & 35 & 35 & 0 & 23 & 23 & 23 & 23 & 0 \\
\hline BFSP & 35 & 35 & 35 & 35 & 0 & 23 & 23 & 23 & 23 & 0 \\
\hline MDSFL & 35 & 35 & 35 & 35 & 0 & 23 & 23 & 23 & 23 & 0 \\
\hline SBHS & 35 & 35 & 35 & 35 & 0 & 23 & 23 & 23 & 23 & 0 \\
\hline SLC & 35 & 35 & 35 & 35 & 0 & 23 & 23 & 23 & 23 & 0 \\
\hline DHS & 35 & 35 & 35 & 35 & 0 & 23 & 23 & 23 & 23 & 0 \\
\hline ABHS & 35 & 35 & 35 & 35 & 0 & 23 & 23 & 23 & 23 & 0 \\
\hline IBBA-RSS & 35 & 35 & 35 & 35 & 0 & 23 & 23 & 23 & 23 & 0 \\
\hline SGO & 35 & 35 & 35 & 35 & 0 & 23 & 23 & 23 & 23 & 0 \\
\hline \multirow[t]{2}{*}{ Algorithm } & \multicolumn{5}{|c|}{ P5, $\operatorname{dim}=15$, optimal value $=481.0694$} & \multicolumn{5}{|c|}{$\mathrm{P} 6, \operatorname{dim}=10$, optimal value $=52$} \\
\hline & Best & Median & Worse & Mean & Std & Best & Median & Worse & Mean & Std \\
\hline $\mathrm{ACO}$ & 481.0694 & NA & 481.0694 & 481.0694 & 0 & 52 & NA & 52 & 52 & 0 \\
\hline SA & 481.0694 & NA & 437.9345 & 453.7506 & 21.1418 & 52 & NA & 50 & 51.8666 & 0.5474 \\
\hline GA & 481.0694 & NA & 481.0694 & 481.0694 & 0 & 52 & NA & 52 & 52 & 0 \\
\hline NGHS & 481.0694 & 481.0694 & 481.0694 & 481.0694 & 0 & 52 & 52 & 52 & 52 & 0 \\
\hline SSO & 481.0694 & NA & 481.0694 & 481.0694 & 0 & 52 & NA & 52 & 52 & 0 \\
\hline CWDO & 481.0694 & NA & 481.0694 & 481.0694 & 0 & 52 & NA & 52 & 52 & 0 \\
\hline BDA & 481.0694 & 481.0694 & 481.0694 & 481.0694 & 0 & 52 & 52 & 52 & 52 & 0 \\
\hline CI & 481.0694 & NA & 412.69 & 449.98 & 10.68 & 51 & NA & 49 & 50.73 & 0.66 \\
\hline IHS & 481.0694 & NA & 437.93 & 478.48 & 10.35 & 50 & NA & 44 & 49.2 & 1.85 \\
\hline PA & 481.0694 & 481.0694 & 437.9345 & 472.4424 & 17.25 & 52 & 52 & 52 & 52 & 0 \\
\hline BFSP & 481.0694 & 481.0694 & 481.0694 & 481.0694 & 0 & 52 & 52 & 52 & 52 & 0 \\
\hline MDSFL & 481.0694 & 481.0694 & 481.0694 & 481.0694 & 0 & 52 & 52 & 52 & 52 & 0 \\
\hline SBHS & 481.0694 & 481.0694 & 481.0694 & 481.0694 & 0 & 52 & 52 & 52 & 52 & 0 \\
\hline SLC & 481.0694 & 481.0694 & 481.0694 & 481.0694 & 0 & 52 & 52 & 52 & 52 & 0 \\
\hline DHS & 481.0694 & 481.0694 & 481.0694 & 481.0694 & 0 & 52 & 52 & 52 & 52 & 0 \\
\hline ABHS & 481.0694 & 481.0694 & 481.0694 & 481.0694 & 0 & 52 & 52 & 52 & 52 & 0 \\
\hline IBBA-RSS & 481.0694 & 481.0694 & 481.0694 & 481.0694 & 0 & 52 & 52 & 52 & 52 & 0 \\
\hline SGO & 481.0694 & 481.0694 & 481.0694 & 481.0694 & 0 & 52 & 52 & 52 & 52 & 0 \\
\hline
\end{tabular}


Table 1

Results of 10 low dimensional 0-1 KP problems, referred from different research paper (Continued)

\begin{tabular}{|c|c|c|c|c|c|c|c|c|c|c|}
\hline \multirow{2}{*}{ Algorithm } & \multicolumn{5}{|c|}{ P7, $\operatorname{dim}=7$, optimal value $=107$} & \multicolumn{5}{|c|}{ P8, $\operatorname{dim}=23$, optimal value $=9767$} \\
\hline & Best & Median & Worse & Mean & Std & Best & Median & Worse & Mean & Std \\
\hline $\mathrm{ACO}$ & 107 & NA & 107 & 107 & 0 & 9765 & NA & 9734 & 9744.867 & 6.5796 \\
\hline SA & 105 & NA & 81 & 84.2 & 7.6762 & 9767 & NA & 9762 & 9765.467 & 2.2086 \\
\hline GA & 107 & NA & 105 & 106.9 & 0.3651 & 9767 & NA & 9767 & 9767 & 0 \\
\hline NGHS & 107 & 107 & 107 & 107 & 0 & 9767 & 9767 & 9767 & 9767 & 0 \\
\hline SSO & 107 & NA & 107 & 107 & 0 & 9767 & NA & 9767 & 9767 & 0 \\
\hline CWDO & 107 & NA & 107 & 107 & 0 & 9767 & NA & 9767 & 9767 & 0 \\
\hline CI & 105 & NA & 79 & 86.6 & 2.99 & 9759 & NA & 9710 & 9753.33 & 11.5 \\
\hline BDA & 107 & 107 & 107 & 107 & 0 & 9767 & 9767 & 9767 & 9767 & 0 \\
\hline IHS & 107 & NA & 93 & 103.98 & 4.48 & 9767 & NA & 9767 & 9767 & 0 \\
\hline $\mathrm{PA}$ & 107 & 105 & 81 & 100.5 & 7.53 & 9767 & 9758 & 9754 & 9755.4 & 0 \\
\hline BFSP & 107 & 107 & 107 & 107 & 0 & 9767 & 9767 & 9767 & 9767 & 0 \\
\hline MDSFL & 107 & 107 & 107 & 107 & 0 & 9767 & 9767 & 9767 & 9767 & 0 \\
\hline SBHS & 107 & 107 & 107 & 107 & 0 & 9767 & 9767 & 9767 & 9767 & 0 \\
\hline SLC & 107 & 107 & 105 & 106.96 & 0.28 & 9767 & 9767 & 9767 & 9767 & 0 \\
\hline DHS & 107 & 107 & 107 & 107 & 0 & 9767 & 9767 & 9767 & 9767 & 0 \\
\hline ABHS & 107 & 107 & 107 & 107 & 0 & 9767 & 9767 & 9767 & 9767 & 0 \\
\hline IBBA-RSS & 107 & 107 & 107 & 107 & 0 & 9767 & 9767 & 9767 & 9767 & 0 \\
\hline \multirow[t]{3}{*}{ SGO } & 107 & 107 & 107 & 107 & 0 & 9767 & 9767 & 9767 & 9767 & 0 \\
\hline & \multicolumn{5}{|c|}{$\mathrm{P} 9, \operatorname{dim}=5$, optimal value $=130$} & \multicolumn{5}{|c|}{$\mathrm{P} 10, \operatorname{dim}=20$, optimal value $=1025$} \\
\hline & Best & Median & Worse & Mean & Std & Best & Median & Worse & Mean & Std \\
\hline $\mathrm{ACO}$ & 130 & NA & 130 & 130 & 0 & 1025 & NA & 1025 & 1025 & 0 \\
\hline SA & 130 & NA & 130 & 130 & 0 & 1025 & NA & 1025 & 1025 & 0 \\
\hline GA & 130 & NA & 130 & 130 & 0 & 1025 & NA & 1019 & 1024.4 & 1.8307 \\
\hline NGHS & 130 & 130 & 130 & 130 & 0 & 1025 & 1025 & 1025 & 1025 & 0 \\
\hline SSO & 130 & NA & 130 & 130 & 0 & 1025 & NA & 1025 & 1025 & 0 \\
\hline CWDO & 130 & NA & 130 & 130 & 0 & 1025 & NA & 1025 & 1025 & 0 \\
\hline CI & 130 & N1 & 106 & 124.6 & 2.89 & 1025 & NA & 892 & 997.7 & 18.6 \\
\hline BDA & 130 & 130 & 130 & 130 & 0 & 1025 & 1025 & 1025 & 1025 & 0 \\
\hline IHS & 130 & NA & 130 & 130 & 0 & 1025 & NA & 1025 & 1025 & 0 \\
\hline $\mathrm{PA}$ & 130 & 130 & 130 & 130 & 0 & 1025 & 1025 & 1025 & 1025 & 0 \\
\hline BFSP & 130 & 130 & 130 & 130 & 0 & 1025 & 1025 & 1025 & 1025 & 0 \\
\hline MDSFL & 130 & 130 & 130 & 130 & 0 & 1025 & 1025 & 1025 & 1025 & 0 \\
\hline SBHS & 130 & 130 & 130 & 130 & 0 & 1025 & 2025 & 1019 & 1024.76 & 1.1758 \\
\hline SLC & 130 & 130 & 130 & 130 & 0 & 1025 & 1025 & 1025 & 1025 & 0 \\
\hline DHS & 130 & 130 & 130 & 130 & 0 & 1025 & 1025 & 1025 & 1025 & 0 \\
\hline ABHS & 130 & 130 & 130 & 130 & 0 & 1025 & 1025 & 1025 & 1025 & 0 \\
\hline IBBA-RSS & 130 & 130 & 130 & 130 & 0 & 1025 & 1025 & 1025 & 1025 & 0 \\
\hline $\mathrm{SGO}$ & 130 & 130 & 130 & 130 & 0 & 1025 & 1025 & 1025 & 1025 & 0 \\
\hline
\end{tabular}

Table 2

AE result of algorithms from Table 1

\begin{tabular}{llll}
\hline Algorithm & Best & Mean & Worse \\
\hline ACO & 0.0020 & 0.0227 & 0.0338 \\
SA & 0.1869 & 2.7327 & 3.7841 \\
GA & 0 & 0.0172 & 0.3040 \\
NGHS & 0 & 0 & 0 \\
SSO & 0 & 0 & 0 \\
CWDO & 0 & 0 & 0 \\
CI & 0.3874 & 4.7625 & 15.1552 \\
BDA & 0 & 0 & 0 \\
IHS & 0.3846 & 1.2070 & 6.2666 \\
PA & 0 & 0.7987 & 3.3399 \\
BFSP & 0 & 0 & 0 \\
MDSFL & 0 & 0.3961 & 0.4185 \\
SBHS & 0 & 0.0035 & 0.2050 \\
SLC & 0 & 0.0037 & 0.1869 \\
DHS & 0 & 0 & 0 \\
\hline ABHS & 0 & 0 & 0 \\
\hline IBBA-RSS & 0 & 0 & 0 \\
\hline
\end{tabular}

From Table 2, we conclude that for all the algorithms except ACO, SA, CI, IHS, AE of best profit are zero. Similarly, except ACO, SA, GA, CI, IHS, PA, MDSFL, SBHS, SLC for all algorithms average error of mean profit is zero. NGHS, SSO, CWDO, BDA, BFSP, DHS, ABHS, IBBA-RSS, SGO algorithms have zero value for an average error of the worst profit. The obtained results from Table 1 and Table 2 we conclude that the proposed BSGO algorithm is competitive with NGHS, SSO, CWDO, BDA, BFSP, HHS, ABHS and IBBA-RSS algorithm and outperforms than ACO, SA, GA, CI, IHS, MDSFL, SBHS and SLC algorithm. 


\subsection{Experiment 2}

In this experiment, to further prove the proficiency of the proposed BSGO algorithm, this algorithm is compared with a binary version of twelve well-known meta-heuristic optimization algorithms including $\mathrm{ABC}$ (Artificial Bee Colony), BA(Bat Algorithm), BH(Black Hole), CS(Cuckoo Search), DE(Differential Evolution), FLA(Frog Leaping Algorithm), GWO(Gray Wolf Optimization), HS(Harmony Search), PSO(Particle Swarm Optimization), TLBO(Teaching Learning Based Optimization), FPA(Flower Pollination Algorithm), FFA (FireFly Algorithm). We have converted these meta-heuristic algorithms to the binary version algorithm by using algorithm 3 and 4 of section 3. Using algorithm 3, we initialize each algorithm, and using algorithm 4, we transform a real-valued individual to binary ones, and using algorithm 5, we have evaluated the fitness value of each individual of algorithms. For comparison of the performance of algorithms, 30 large-scale 0-1 knapsack problems are introduced. These 30 large-scale 0-1 knapsack problems are of three categories: uncorrelated, weakly correlated and strongly correlated. Three kinds of correlation characteristics of profit and weight such as uncorrelated, weakly correlated and strongly correlated, are shown in Table A2 of Appendix A. For example, the nature of uncorrelated items, weakly correlated items and strongly correlated items of 200 dimensions are depicted in Fig. 2. Here function rand(a, b) returns a integer drawn from uniform distribution in interval $[a, b]$, where $a=10$ and $b=30$. Here each group includes 10 large-scale 0-1 KPs problems generated randomly whose dimension is 100, 200, 300, 500, 700, 1000, 1500, 2000, 3000 and 5000 respectively. These 30 0-1 KPs are represented by ucdata1, ucdata2,...., ucdata10, wcdata1, wcdata2,..., wcdata10, scdata1, scdata $2, \ldots$, scdata10 respectively. Additionally, the maximum capacity of knapsack equals 0.75 times of the sum of the weights. It is worth noting that these datasets are created only once using a random generator and kept constant for all experiments.

To reflect fairness of the comparison process, common control parameters such as maximum number function evaluation is deemed to be the same for all algorithms as 10,000. For that, we have considered the maximum number of iteration is 200 , and population size is 25 for $\mathrm{ABC}, \mathrm{CS}, \mathrm{SGO}, \mathrm{TLBO}$, and for other algorithms, population size is 50 (the function is evaluated twice in each iteration for ABC, CS, SGO, and TLBO algorithm). The other algorithm-specific parameters are given in Table 3. The experiments are conducted in MATLAB 2016a on an Intel Core i5, 8 GB memory laptop in Windows 10 environment

For each problem, algorithms are run 30 times, starting from different populations randomly generated. Statistical results in terms of best value, mean value, median value, worse value and corresponding standard deviation are reported in Tables. The comparative results achieved by 13 algorithms ABC, BA, BH, CS, DE, FLA, GWO, HS, PSO, TLBO, FPA, FFA and SGO on uncorrelated, weakly correlated and strongly correlated 0-1 KPs are presented in Tables 4-6 respectively. The best results on each problem among all 13 algorithms are bolded in each table. As optimal profits are unknown AE (average error) of the best profit and/or mean profit and/or worse profit of results are not calculated. The convergence characteristics of all the algorithms in the first 50 iterations for all the uncorrelated, weakly correlated and strongly correlated 0-1 large-scale KP problems are depicted in Fig.3, Fig.4 and Fig.5 respectively.

Table 3

The setting of parameters for algorithms

\begin{tabular}{lll}
\hline Algorithm & $\begin{array}{l}\text { Function Evaluation } \\
\text { in each iteration }\end{array}$ & Other parameters \\
\hline ABC & 2 & Number of food sources $=25$, maximum search time $=100$ \\
PSO & 1 & Fully connected, cognitive parameter $=2$, social parameter=2, inertia of weight $=0.5$ \\
DE & 1 & $\mathrm{~F}=0.9, \mathrm{CR}=0.1$ \\
CS & 2 & $P_{a}=0.25$ \\
GWO & 1 & The $\mathrm{a}=2-2 *\left(\right.$ iter $/$ iter $\left.r_{\text {max }}\right)$ \\
FFA & 1 & alpha $=0.2$, gamma $=1.0$, delta $=0.97$. \\
FLA & 1 & $\mathrm{M}=5, \mathrm{~N}=10$ \\
FPA & 1 & Switching probability $\mathrm{P}=0.8$, \\
BA & 1 & alpha $=0.9$, gamma $=0.9$ \\
TLBO & 2 & There is no such parameter to set value \\
SGO & 2 & There is only one parameter $\mathrm{C}$ called a self-introspection factor. Value of C is 0.2 \\
BH & 1 & There is no parameter \\
HS & 1 & hmcr $=0.9$, par $=0.3$, bw $=0.01$ \\
\hline
\end{tabular}
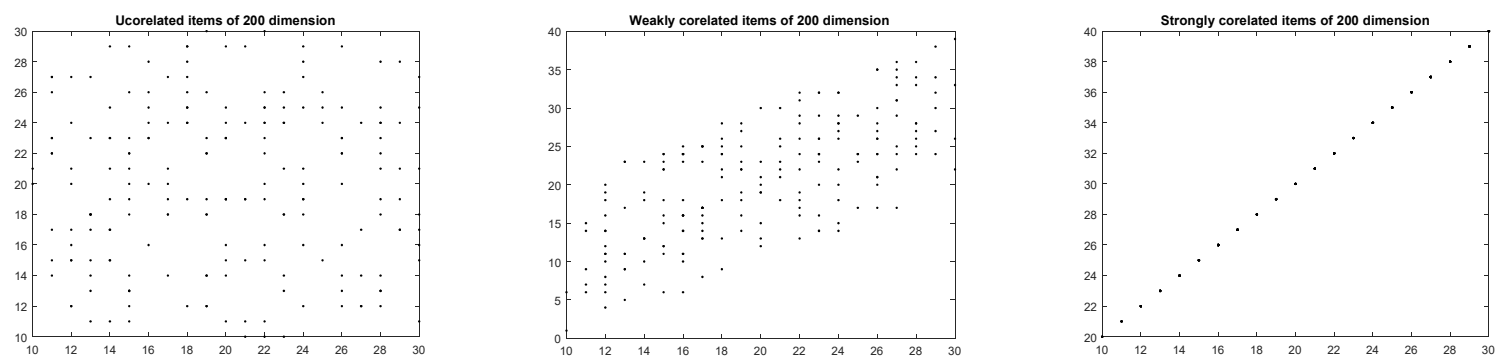

Fig. 2. Nature of uncorrelated items, weakly correlated items and strongly correlated items of 200 
Table 4

Results of UC data high dimensional 01knapsack problem, 30 different runs, 200 generation

\begin{tabular}{|c|c|c|c|c|c|c|c|c|c|c|c|c|}
\hline \multirow[t]{2}{*}{ Algorithm } & \multicolumn{6}{|c|}{ UCdata1, dim $=100$} & \multicolumn{6}{|c|}{ UCdata $2, \operatorname{dim}=200$} \\
\hline & Best & Median & Worse & Mean & Std & WRS & Best & Median & Worse & Mean & Std & WRS \\
\hline $\mathrm{ABC}$ & 1632 & 1627 & 1618 & $1.6078 \mathrm{e}+03$ & 6.1008 & - & 3278 & 3232 & 3199 & $3.2308 \mathrm{e}+03$ & 24.5700 & - \\
\hline BA & 1641 & 1611 & 1581 & $1.6098 \mathrm{e}+03$ & 18.4585 & - & 3240 & 3148 & 3109 & $3.1481 \mathrm{e}+03$ & 26.5056 & - \\
\hline BH & 1608 & 1563 & 1550 & $1.5662 \mathrm{e}+03$ & 13.7883 & - & 3126 & 3078 & 3052 & $3.0793 \mathrm{e}+03$ & 17.8641 & - \\
\hline $\mathrm{CS}$ & 1605 & 1592 & 1574 & 1590 & 8.5258 & - & 3203 & 3133 & 3108 & $3.1354 \mathrm{e}+03$ & 22.9895 & - \\
\hline $\mathrm{DE}$ & 1613 & 1578 & 1564 & $1.5792 \mathrm{e}+03$ & 12.4781 & - & 3167 & 3123 & 3087 & 3.1225 & 20.4413 & - \\
\hline GWO & 1604 & 1568 & 1547 & $1.5662 \mathrm{e}+03$ & 13.1282 & - & 3174 & 3091 & 3056 & $3.0935 \mathrm{e}+03$ & 24.5746 & - \\
\hline HS & 1594 & 1576 & 1561 & $1.5750 \mathrm{e}+03$ & 9.0038 & - & 3152 & 3114 & 3083 & $3.1122 \mathrm{e}+03$ & 18.6357 & - \\
\hline PSO & 1618 & 1581 & 1561 & $1.5831 \mathrm{e}+03$ & 14.2101 & - & 3169 & 3123 & 3083 & $3.1219 \mathrm{e}+03$ & 21.9018 & - \\
\hline TLBO & 1607 & 1584 & 1570 & $1.5829 \mathrm{e}+03$ & 8.2876 & - & 3165 & 3118 & 3089 & $3.1205 \mathrm{e}+03$ & 20.3618 & - \\
\hline SGO & 1651 & 1612 & 1573 & $1.6108 \mathrm{e}+03$ & 18.9143 & & 3321 & 3232 & 3117 & $3.2231 \mathrm{e}+03$ & 57.7281 & \\
\hline FPA & 1618 & 1579 & 1561 & $1.5786 \mathrm{e}+03$ & 12.5574 & - & 3151 & 3104 & 3086 & $3.1075 e+03$ & 17.4726 & - \\
\hline FFA & 1633 & 1614 & 1604 & $1.6161 \mathrm{e}+03$ & 7.7029 & - & 3218 & 3179 & 3157 & $3.1792 \mathrm{e}+03$ & 15.4393 & - \\
\hline \multirow[t]{2}{*}{ Algorithm } & \multicolumn{6}{|c|}{ UCdata $3, \operatorname{dim}=300$} & \multicolumn{6}{|c|}{ UCdata $4, \operatorname{dim}=500$} \\
\hline & Best & Median & Worse & Mean & Std & WRS & Best & Median & Worse & Mean & Std & WRS \\
\hline $\mathrm{ABC}$ & 4693 & 4592 & 4525 & $4.5931 \mathrm{e}+03$ & 45.4201 & $\begin{array}{ll}- \\
-\end{array}$ & 7225 & 7049 & 6896 & $7.0385 \mathrm{E}+03$ & 84.6428 & - \\
\hline BA & 4764 & 4582 & 4537 & $4.5875 \mathrm{e}+03$ & 45.4796 & - & 7669 & 7558 & 7454 & $7.5456 \mathrm{E}+03$ & 58.4881 & - \\
\hline BH & 4586 & 4471 & 4431 & $4.4826 e+03$ & 40.1561 & - & 7660 & 7380 & 7257 & $7.3950 \mathrm{E}+03$ & 90.8084 & - \\
\hline $\mathrm{CS}$ & 4615 & 4563 & 4519 & $4.5621 \mathrm{e}+03$ & 28.1061 & - & 7662 & 7521 & 7456 & $7.5274 \mathrm{E}+03$ & 55.9819 & - \\
\hline $\mathrm{DE}$ & 4595 & 4548 & 4493 & $4.5418 \mathrm{e}+03$ & 26.7681 & - & 7592 & 7480 & 7410 & $7.4774 \mathrm{E}+03$ & 44.7811 & - \\
\hline GWO & 4552 & 4493 & 4443 & 4.4933 & 29.6501 & - & 7544 & 7422 & 7337 & $7.4241 \mathrm{E}+03$ & 52.1320 & - \\
\hline HS & 4636 & 4533 & 4487 & $4.5376 e+03$ & 30.7745 & - & 7723 & 7454 & 7388 & $7.4713 \mathrm{E}+03$ & 73.9018 & - \\
\hline PSO & 4619 & 4569 & 4514 & $4.5658 \mathrm{e}+03$ & 28.8915 & - & 7780 & 7531 & 7401 & $7.5436 \mathrm{E}+03$ & 89.1398 & - \\
\hline TLBO & 4628 & 4543 & 4506 & $4.5477 \mathrm{e}+03$ & 24.9876 & - & 7637 & 7469 & 7413 & 7483 & 57.5410 & - \\
\hline SGO & 4871 & 4807 & 4697 & $4.7996 e+03$ & 48.5100 & & 8238 & 8081 & 7844 & $8.0689 E+03$ & 102.8319 & \\
\hline FPA & 4601 & 4523 & 4485 & $4.5260 \mathrm{e}+03$ & 28.8952 & - & 7586 & 7455 & 7384 & $7.4661 \mathrm{E}+03$ & 53.2009 & - \\
\hline FFA & 4664 & 4637 & 4614 & $4.6355 \mathrm{E}+03$ & 15.4043 & - & 7700 & 7645 & 7616 & $7.6532 \mathrm{E}+03$ & 27.5477 & - \\
\hline \multirow[t]{2}{*}{ Algorithm } & \multicolumn{6}{|c|}{ UCdata5, dim $=700$} & & & UCdat: & $\mathrm{a} 6, \operatorname{dim}=1000$ & & \\
\hline & Best & Median & Worse & Mean & Std & WRS & Best & Median & Worse & Mean & Std & WRS \\
\hline $\mathrm{ABC}$ & 9711 & 9377 & 9192 & $9.3811 \mathrm{e}+03$ & 116.4466 & - & 12889 & 12496 & 12349 & $1.2532 \mathrm{e}+04$ & 142.7659 & - \\
\hline BA & 10628 & 10388 & 10337 & $1.0413 \mathrm{e}+04$ & 69.7836 & - & 14923 & 14613 & 14506 & $1.4627 \mathrm{e}+04$ & 114.2712 & - \\
\hline BH & 10413 & 10220 & 10156 & $1.0237 \mathrm{e}+04$ & 69.5761 & - & 14572 & 14359 & 14212 & $1.4362 \mathrm{e}+04$ & 95.2886 & - \\
\hline $\mathrm{CS}$ & 10586 & 10364 & 10315 & $1.0401 \mathrm{e}+04$ & 77.2193 & - & 14692 & 14546 & 14488 & $1.4561 \mathrm{e}+04$ & 58.2545 & - \\
\hline $\mathrm{DE}$ & 10545 & 10342 & 10271 & $1.0348 \mathrm{e}+04$ & 62.4032 & - & 14649 & 14511 & 14394 & 14500 & 69.6459 & - \\
\hline GWO & 10389 & 10231 & 10164 & $1.0239 \mathrm{e}+04$ & 59.1272 & - & 14773 & 14402 & 14312 & $1.4421 \mathrm{e}+04$ & 98.1866 & - \\
\hline HS & 10520 & 10321 & 10273 & $1.0340 \mathrm{e}+04$ & 67.6216 & - & 14655 & 14449 & 14328 & $1.4466 e+04$ & 83.7556 & - \\
\hline PSO & 10728 & 10465 & 10352 & $1.0478 \mathrm{e}+04$ & 101.3282 & - & 15145 & 14862 & 14643 & $1.4849 \mathrm{e}+04$ & 135.1496 & - \\
\hline TLBO & 10541 & 10358 & 10274 & $1.0370 \mathrm{e}+04$ & 65.5183 & - & 14751 & 14516 & 14400 & $1.4534 \mathrm{e}+04$ & 97.5332 & - \\
\hline SGO & 11628 & 11373 & 10980 & 11339 & 166.3424 & & 16397 & 16146 & 15878 & $1.6148 e+04$ & 135.4209 & \\
\hline FPA & 10620 & 10294 & 10222 & $1.0312 \mathrm{e}+04$ & 89.0557 & - & 14691 & 14445 & 14349 & $1.4469 e+04$ & 92.9166 & - \\
\hline FFA & 10718 & 10584 & 10527 & $1.0590 \mathrm{e}+04$ & 39.5295 & - & 15148 & 14807 & 14732 & $1.4833 \mathrm{e}+04$ & 94.4428 & - \\
\hline Algorithm & & & UCdat & $7, \operatorname{dim}=1500$ & & & & & UCdate & $\mathrm{a} 8, \mathrm{dim}=2000$ & & \\
\hline & Best & Median & Worse & Mean & Std & WRS & Best & Median & Worse & Mean & Std & WRS \\
\hline $\mathrm{ABC}$ & 18247 & 17524 & 17307 & $1.7557 \mathrm{e}+04$ & 176.4488 & - & 23314 & 22804 & 22527 & $2.2865 \mathrm{e}+04$ & 212.1212 & - \\
\hline $\mathrm{BA}$ & 21548 & 21181 & 21034 & $2.1204 \mathrm{e}+04$ & 129.6044 & - & 28611 & 28257 & 28025 & $2.8246 \mathrm{e}+04$ & 145.8881 & - \\
\hline BH & 21051 & 20846 & 20707 & $2.0858 \mathrm{e}+04$ & 89.5965 & - & 28117 & 27775 & 27591 & $2.7785 e+04$ & 136.9804 & - \\
\hline $\mathrm{CS}$ & 21329 & 21134 & 21051 & $2.1150 \mathrm{e}+04$ & 65.3697 & - & 28267 & 28072 & 27936 & $2.8082 \mathrm{e}+04$ & 100.6582 & - \\
\hline $\mathrm{DE}$ & 21364 & 21064 & 20937 & $2.1081 \mathrm{e}+04$ & 114.3904 & - & 28240 & 27970 & 27812 & $2.7979 e+04$ & 117.3320 & - \\
\hline GWO & 21148 & 20936 & 20802 & $2.0935 \mathrm{e}+04$ & 84.5506 & - & 28238 & 27875 & 27749 & $2.7897 \mathrm{e}+04$ & 122.0125 & - \\
\hline HS & 21426 & 21020 & 20898 & $2.1050 \mathrm{e}+04$ & 118.0167 & - & 28346 & 27864 & 27689 & $2.7870 e+04$ & 135.0396 & - \\
\hline PSO & 22096 & 21718 & 21332 & $2.1713 \mathrm{e}+04$ & 164.9957 & - & 29693 & 28954 & 28678 & $2.8989 \mathrm{e}+04$ & 241.1206 & - \\
\hline TLBO & 21447 & 21082 & 20949 & $2.1109 e+04$ & 113.0351 & - & 28323 & 28028 & 27788 & $2.8024 \mathrm{e}+04$ & 157.4332 & - \\
\hline SGO & 24397 & 23928 & 23270 & $2.3876 e+04$ & 298.9341 & & 32687 & 32160 & 31639 & $3.2137 e+04$ & 264.3118 & \\
\hline FPA & 21172 & 20981 & 20879 & $2.0988 \mathrm{e}+04$ & 70.0304 & - & 28361 & 27878 & 27756 & $2.7907 e+04$ & 146.5758 & - \\
\hline FFA & 21700 & 21429 & 21325 & $2.1451 \mathrm{e}+04$ & 96.0837 & - & 28607 & 28392 & 28281 & $2.8398 \mathrm{e}+04$ & 84.7697 & - \\
\hline Algorithm & & & UCdat & $9, \operatorname{dim}=3000$ & & & & & UCdata & $110, \mathrm{dim}=5000$ & & \\
\hline & Best & Median & Worse & Mean & Std & WRS & Best & Median & Worse & Mean & Std & WRS \\
\hline $\mathrm{ABC}$ & 33912 & 33131 & 32872 & $3.3191 \mathrm{e}+04$ & 297.8634 & - & 53731 & 53104 & 52701 & $5.3157 \mathrm{e}+04$ & 271.1119 & - \\
\hline $\mathrm{BA}$ & 42658 & 41803 & 41498 & $4.1926 \mathrm{e}+04$ & 330.8225 & - & 69429 & 68643 & 68110 & $6.8646 \mathrm{e}+04$ & 366.4497 & - \\
\hline BH & 41652 & 41139 & 40895 & $4.1160 \mathrm{e}+04$ & 188.6589 & - & 67868 & 67240 & 67240 & $6.7300 \mathrm{e}+04$ & 259.4373 & - \\
\hline $\mathrm{CS}$ & 41727 & 41518 & 41375 & $4.1525 \mathrm{e}+04$ & 95.3210 & - & 68475 & 67823 & 67568 & $6.7846 e+04$ & 216.4741 & - \\
\hline $\mathrm{DE}$ & 41768 & 41472 & 41260 & $4.1484 \mathrm{e}+04$ & 130.8128 & - & 67993 & 67678 & 67448 & $6.7689 e+04$ & 152.2831 & - \\
\hline GWO & 41714 & 41300 & 41154 & $4.1319 \mathrm{e}+04$ & 143.1373 & - & 67887 & 67429 & 67248 & $6.7461 \mathrm{e}+04$ & 138.4048 & - \\
\hline $\mathrm{HS}$ & 41975 & 41290 & 41092 & $4.1314 \mathrm{e}+04$ & 187.1917 & - & 67990 & 67347 & 67087 & $6.7381 e+04$ & 196.6028 & - \\
\hline PSO & 43640 & 43162 & 42790 & $4.3204 \mathrm{e}+04$ & 203.8988 & - & 71990 & 71010 & 70500 & $7.0997 \mathrm{e}+04$ & 361.0556 & - \\
\hline TLBO & 42018 & 41639 & 41373 & $4.1604 \mathrm{e}+04$ & 168.7509 & - & 68362 & 67804 & 67529 & $6.7829 e+04$ & 191.4581 & - \\
\hline SGO & 48920 & 48107 & 46903 & $4.8112 \mathrm{e}+04$ & 443.9315 & & 80377 & 79644 & 77802 & $7.9497 e+04$ & 684.2918 & \\
\hline FPA & 41836 & 41370 & 41219 & $4.1407 e+04$ & 135.5978 & - & 68188 & 67519 & 67308 & $6.7577 e+04$ & 229.3645 & - \\
\hline FFA & 44658 & 43803 & 43498 & $4.3926 \mathrm{e}+04$ & 330.8225 & - & 70429 & 69643 & 69110 & $6.9646 \mathrm{e}+04$ & 366.4497 & - \\
\hline
\end{tabular}


Table 5

Results of WC data high dimensional 01kanshap problem , 30 different runs, 200 generation

\begin{tabular}{|c|c|c|c|c|c|c|c|c|c|c|c|c|}
\hline \multirow[t]{2}{*}{ Algorithm } & \multicolumn{6}{|c|}{ WCdata $1, \operatorname{dim}=100$} & \multicolumn{6}{|c|}{ WCdata $2, \operatorname{dim}=200$} \\
\hline & Best & Median & Worse & Mean & Std & WRS & Best & Median & Worse & Mean & Std & WRS \\
\hline $\mathrm{ABC}$ & 1651 & 1639 & 1631 & $1.6397 \mathrm{e}+03$ & 5.4351 & - & 3364 & 3303 & 3286 & $3.3096 \mathrm{e}+03$ & 19.2291 & - \\
\hline BA & 1638 & 1612 & 1591 & $1.6107 \mathrm{e}+03$ & 12.4428 & - & 3304 & 3254 & 3227 & $3.2581 \mathrm{e}+03$ & 20.8143 & - \\
\hline BH & 1604 & 1581 & 1570 & $1.5813 \mathrm{e}+03$ & 8.8518 & - & 3233 & 3201 & 3176 & $3.2009 \mathrm{e}+03$ & 16.4437 & - \\
\hline $\mathrm{CS}$ & 1614 & 1597 & 1587 & $1.5978 \mathrm{e}+03$ & 7.9381 & - & 3279 & 3244 & 3225 & $3.2427 \mathrm{e}+03$ & 14.3429 & - \\
\hline $\mathrm{DE}$ & 1609 & 1590 & 1582 & $1.5929 \mathrm{e}+03$ & 7.0844 & - & 3265 & 3227 & 3214 & $3.2319 \mathrm{e}+03$ & 14.6686 & - \\
\hline GWO & 1606 & 1584 & 1571 & $1.5843 \mathrm{e}+03$ & 9.6538 & - & 3249 & 3204 & 3181 & $3.2058 \mathrm{e}+03$ & 17.1325 & - \\
\hline HS & 1625 & 1587 & 1577 & $1.5885 \mathrm{e}+03$ & 9.8076 & - & 3280 & 3215 & 3197 & $3.2196 \mathrm{e}+03$ & 20.4984 & - \\
\hline PSO & 1618 & 1597 & 1583 & $1.5971 \mathrm{e}+03$ & 8.2334 & - & 3264 & 3237 & 3205 & $3.2363 \mathrm{e}+03$ & 17.2230 & - \\
\hline TLBO & 1610 & 1591 & 1584 & $1.5929 \mathrm{e}+03$ & 7.8228 & - & 3291 & 3230 & 3208 & $3.2299 \mathrm{e}+03$ & 16.4290 & - \\
\hline SGO & 1641 & 1609 & 1587 & $1.6086 e+03$ & 1587 & & 3375 & 3321 & 3259 & $3.3215 e+03$ & 32.4098 & \\
\hline FPA & 1622 & 1590 & 1578 & $1.5918 \mathrm{e}+03$ & 9.7651 & - & 3276 & 3229 & 3206 & $3.2307 \mathrm{e}+03$ & 18.3343 & - \\
\hline FFA & 1627 & 1615 & 1609 & $1.6158 \mathrm{e}+03$ & 4.1992 & - & 3328 & 3282 & 3265 & $3.2854 \mathrm{e}+03$ & 15.7841 & - \\
\hline \multirow[t]{2}{*}{ Algorithm } & \multicolumn{6}{|c|}{ WCdata3, dim $=300$} & \multicolumn{6}{|c|}{ WCdata 4, dim $=500$} \\
\hline & Best & Median & Worse & Mean & Std & WRS & Best & Median & Worse & Mean & Std & WRS \\
\hline $\mathrm{ABC}$ & 4615 & 4535 & 4487 & $4.5352 \mathrm{e}+03$ & 32.1259 & - & 7243 & 7083 & 6910 & 7071 & 98.5719 & - \\
\hline BA & 4624 & 4551 & 4487 & $4.5474 \mathrm{e}+03$ & 31.1012 & - & 7742 & 7579 & 7483 & $7.5901 \mathrm{e}+03$ & 68.0767 & - \\
\hline BH & 4494 & 4444 & 4399 & $4.4443 e+03$ & 25.4639 & - & 7519 & 7374 & 7302 & $7.3868 \mathrm{e}+03$ & 60.4635 & - \\
\hline $\mathrm{CS}$ & 4569 & 4520 & 4489 & $4.5236 \mathrm{e}+03$ & 22.4171 & - & 7626 & 7533 & 7479 & $7.5398 \mathrm{e}+03$ & 36.2197 & - \\
\hline $\mathrm{DE}$ & 4537 & 4505 & 4466 & $4.5035 \mathrm{e}+03$ & 21.6568 & - & 7673 & 7526 & 7426 & $7.5189 \mathrm{e}+03$ & 64.6659 & - \\
\hline GWO & 4517 & 4450 & 4414 & $4.4555 \mathrm{e}+03$ & 28.0132 & - & 7629 & 7409 & 7347 & $7.4294 \mathrm{e}+03$ & 61.4528 & - \\
\hline HS & 4564 & 4492 & 4445 & $4.4905 \mathrm{e}+03$ & 30.3198 & - & 7612 & 7518 & 7429 & $7.5071 \mathrm{e}+03$ & 51.8442 & - \\
\hline PSO & 4608 & 4504 & 4452 & $4.5046 \mathrm{e}+03$ & 34.6008 & - & 7695 & 7559 & 7449 & $7.5639 \mathrm{e}+03$ & 64.7003 & - \\
\hline TLBO & 4534 & 4501 & 4465 & $4.5005 \mathrm{e}+03$ & 20.0615 & - & 7715 & 7495 & 7445 & $7.5061 \mathrm{e}+03$ & 60.6626 & - \\
\hline SGO & 4811 & 4702 & 4589 & $4.6923 \mathrm{e}+03$ & 55.3073 & & 8104 & 7868 & 7706 & $7.8660 \mathrm{e}+03$ & 101.7087 & \\
\hline FPA & 4560 & 4487 & 4442 & $4.4902 \mathrm{e}+03$ & 29.7303 & - & 7585 & 7479 & 7415 & $7.4848 \mathrm{e}+03$ & 47.6161 & - \\
\hline FFA & 4656 & 4578 & 4543 & $4.5818 \mathrm{e}+03$ & 22.3243 & - & 7829 & 7694 & 7643 & $7.7009 \mathrm{e}+03$ & 43.0672 & - \\
\hline \multirow[t]{2}{*}{ Algorithm } & \multicolumn{6}{|c|}{ WCdata5, dim $=700$} & & & $\mathrm{WCd}$ & $\mathrm{ab}, \mathrm{dim}=1000$ & & \\
\hline & Best & Median & Worse & Mean & Std & WRS & Best & Median & Worse & Mean & Std & WRS \\
\hline $\mathrm{ABC}$ & 9281 & 8974 & 8817 & $8.9832 \mathrm{e}+03$ & 116.1054 & - & 12846 & 12496 & 12148 & 12465 & 186.5553 & - \\
\hline BA & 10279 & 10114 & 10007 & $1.0130 \mathrm{e}+04$ & 76.9885 & - & 14791 & 14538 & 14437 & $1.4549 \mathrm{e}+04$ & 82.8239 & - \\
\hline $\mathrm{BH}$ & 10064 & 9860 & 9805 & $9.8783 e+03$ & 61.2498 & - & 14545 & 14271 & 14121 & $1.4269 \mathrm{e}+04$ & 107.7963 & - \\
\hline $\mathrm{CS}$ & 10296 & 10056 & 9979 & $1.0079 \mathrm{e}+04$ & 80.1256 & - & 14620 & 14523 & 14393 & $1.4508 \mathrm{e}+04$ & 65.7085 & - \\
\hline $\mathrm{DE}$ & 10210 & 10022 & 9917 & $1.0032 \mathrm{e}+04$ & 72.9858 & - & 14610 & 14396 & 14288 & $1.4409 \mathrm{e}+04$ & 84.7410 & - \\
\hline GWO & 10160 & 9950 & 9852 & $9.9545 \mathrm{e}+03$ & 78.7951 & - & 14683 & 14322 & 14229 & $1.4352 \mathrm{e}+04$ & 103.6125 & - \\
\hline $\mathrm{HS}$ & 10126 & 10021 & 9928 & $1.0018 \mathrm{e}+04$ & 57.2830 & - & 14645 & 14391 & 14263 & $1.4393 \mathrm{e}+04$ & 92.4135 & - \\
\hline PSO & 10359 & 10112 & 10022 & $1.0156 \mathrm{e}+04$ & 102.0322 & - & 15211 & 14729 & 14417 & $1.4745 \mathrm{e}+04$ & 190.4419 & - \\
\hline TLBO & 10187 & 10045 & 9967 & $1.0053 e+04$ & 56.0603 & - & 14648 & 14453 & 14325 & $1.4452 \mathrm{e}+04$ & 70.8422 & - \\
\hline SGO & 11084 & 10967 & 10722 & $1.0943 e+04$ & 89.0441 & & 15990 & 15854 & 15290 & $1.5813 e+04$ & 162.1211 & \\
\hline FPA & 10175 & 10006 & 9923 & $1.0020 \mathrm{e}+04$ & 70.5165 & - & 14632 & 14367 & 14295 & $1.4395 \mathrm{e}+04$ & 74.7997 & - \\
\hline FFA & 10417 & 10273 & 10193 & $1.0273 \mathrm{e}+04$ & 53.6731 & - & 14941 & 14725 & 14636 & $1.4723 \mathrm{e}+04$ & 67.7216 & - \\
\hline Algorithm & & & WCda & $7, \operatorname{dim}=1500$ & & & & & $\mathrm{WCd}$ & $98, \operatorname{dim}=2000$ & & \\
\hline & Best & Median & Worse & Mean & Std & WRS & Best & Median & Worse & Mean & Std & WRS \\
\hline $\mathrm{ABC}$ & 18172 & 17763 & 17476 & $1.7751 \mathrm{e}+04$ & 185.2326 & - & 23025 & 22724 & 22427 & $2.2688 \mathrm{e}+04$ & 180.0892 & - \\
\hline BA & 21989 & 21533 & 21249 & $2.1527 \mathrm{e}+04$ & 161.4532 & - & 28401 & 27996 & 27762 & $2.7997 \mathrm{e}+04$ & 151.7021 & - \\
\hline $\mathrm{BH}$ & 21360 & 21078 & 20940 & $2.1094 \mathrm{e}+04$ & 103.9461 & - & 28015 & 27544 & 27385 & $2.7597 e+04$ & 152.0531 & - \\
\hline $\mathrm{CS}$ & 21633 & 21356 & 21266 & $2.1379 \mathrm{e}+04$ & 93.7829 & - & 28296 & 27891 & 27732 & $2.7897 \mathrm{e}+04$ & 125.6355 & - \\
\hline $\mathrm{DE}$ & 21687 & 21308 & 21159 & $2.1307 \mathrm{e}+04$ & 121.7259 & - & 28143 & 27791 & 27638 & $2.7820 \mathrm{e}+04$ & 150.7502 & - \\
\hline GWO & 21523 & 21174 & 21029 & $2.1192 \mathrm{e}+04$ & 115.7313 & - & 27852 & 27670 & 27485 & $2.7653 \mathrm{e}+04$ & 105.7725 & - \\
\hline HS & 21749 & 21312 & 21117 & $2.1312 \mathrm{e}+04$ & 153.5591 & - & 28026 & 27732 & 27563 & $2.7744 \mathrm{e}+04$ & 114.1172 & - \\
\hline PSO & 22466 & 21896 & 21554 & $2.1897 \mathrm{e}+04$ & 206.7262 & - & 29293 & 28714 & 28372 & $2.8728 \mathrm{e}+04$ & 211.3318 & - \\
\hline TLBO & 21699 & 21349 & 21185 & $2.1355 \mathrm{e}+04$ & 124.6619 & - & 28320 & 27883 & 27719 & $2.7918 \mathrm{e}+04$ & 151.2393 & - \\
\hline SGO & 24233 & 23731 & 23303 & $2.3699 e+04$ & 193.9530 & & 32065 & 31647 & 30904 & $3.1612 e+04$ & 259.3154 & \\
\hline FPA & 21442 & 21260 & 21084 & $2.1258 \mathrm{e}+04$ & 119.7747 & - & 28020 & 27708 & 27549 & $2.7723 \mathrm{e}+04$ & 123.9565 & - \\
\hline FFA & 21822 & 21660 & 21545 & $2.1669 \mathrm{e}+04$ & 77.6342 & - & 28460 & 28230 & 28061 & $2.8233 \mathrm{e}+04$ & 106.3678 & - \\
\hline Algorithm & & & WCda & $9, \operatorname{dim}=3000$ & & & & & WCda & $10, \operatorname{dim}=5000$ & & \\
\hline & Best & Median & Worse & Mean & Std & WRS & Best & Median & Worse & Mean & Std & WRS \\
\hline $\mathrm{ABC}$ & 33848 & 33165 & 32741 & $3.3178 \mathrm{e}+04$ & 266.4967 & - & 53869 & 53022 & 52626 & $5.3063 \mathrm{e}+04$ & 363.7348 & - \\
\hline BA & 42510 & 41986 & 41620 & $4.1981 \mathrm{e}+04$ & 222.1270 & - & 68990 & 68323 & 67944 & $6.8339 \mathrm{e}+04$ & 274.9376 & - \\
\hline BH & 41702 & 41232 & 40972 & $4.1260 \mathrm{e}+04$ & 202.1042 & - & 67582 & 67278 & 67004 & $6.7274 \mathrm{e}+04$ & 150.4867 & - \\
\hline $\mathrm{CS}$ & 42314 & 41710 & 41513 & $4.1715 \mathrm{e}+04$ & 170.6706 & - & 68377 & 67799 & 67626 & $6.7853 e+04$ & 207.0322 & - \\
\hline $\mathrm{DE}$ & 41835 & 41575 & 41329 & $4.1568 \mathrm{e}+04$ & 138.6789 & - & 68176 & 67731 & 67375 & $6.7677 e+04$ & 196.9331 & - \\
\hline GWO & 41762 & 41373 & 41196 & $4.1389 \mathrm{e}+04$ & 133.3942 & - & 67789 & 67447 & 67218 & $6.7442 \mathrm{e}+04$ & 150.1487 & - \\
\hline HS & 41898 & 41416 & 41200 & $4.1449 \mathrm{e}+04$ & 170.2524 & - & 68129 & 67313 & 67118 & $6.7370 \mathrm{e}+04$ & 210.9200 & - \\
\hline PSO & 43940 & 43148 & 42677 & $4.3197 \mathrm{e}+04$ & 282.2162 & - & 72156 & 71054 & 70159 & $7.0985 \mathrm{e}+04$ & 468.9905 & - \\
\hline TLBO & 41994 & 41593 & 41389 & $4.1628 \mathrm{e}+04$ & 168.3593 & - & 68332 & 67812 & 67547 & $6.7823 e+04$ & 184.7154 & - \\
\hline SGO & 48463 & 47904 & 47063 & $4.7849 e+04$ & 366.4701 & & 80000 & 79322 & 78473 & $7.9215 e+04$ & 408.5615 & \\
\hline FPA & 41902 & 41509 & 41305 & $4.1517 \mathrm{e}+04$ & 159.3380 & - & 68124 & 67521 & 67354 & $6.7569 \mathrm{e}+04$ & 180.6549 & - \\
\hline FFA & 44510 & 43986 & 43620 & $4.3981 \mathrm{e}+04$ & 222.1270 & - & 70990 & 70323 & 70944 & $6.8339 \mathrm{e}+04$ & & - \\
\hline
\end{tabular}


Table 6

Results of SC data high dimensional 01knapsack problem, 30 different runs, 200 generation

\begin{tabular}{|c|c|c|c|c|c|c|c|c|c|c|c|c|}
\hline \multirow[t]{2}{*}{ Algorithm } & \multicolumn{6}{|c|}{ SCdata1, dim $=100$} & \multicolumn{6}{|c|}{ SCdata2, $\operatorname{dim}=200$} \\
\hline & Best & Median & Worse & Mean & Std & WRS & Best & Median & Worse & Mean & Std & WRS \\
\hline $\mathrm{ABC}$ & 2311 & 2292 & 2287 & $2.2938 \mathrm{e}+03$ & 5.3439 & - & 4702 & 4679 & 4668 & $4.6794 \mathrm{e}+03$ & 9.5581 & - \\
\hline $\mathrm{BA}$ & 2312 & 2302 & 2296 & $2.3033 \mathrm{e}+03$ & 4.2938 & - & 4702 & 4681 & 4670 & $4.6833 \mathrm{e}+03$ & 9.5490 & - \\
\hline $\mathrm{BH}$ & 2306 & 2294 & 2290 & $2.2952 \mathrm{e}+03$ & 3.9427 & - & 4691 & 4667 & 4655 & $4.6665 \mathrm{e}+03$ & 8.5328 & - \\
\hline CS & 2320 & 2306 & 2301 & $2.3064 \mathrm{e}+03$ & 4.7894 & - & 4702 & 4681 & 4673 & $4.6824 \mathrm{e}+03$ & 6.4680 & - \\
\hline $\mathrm{DE}$ & 2312 & 2302 & 2295 & $2.3025 e+03$ & 5.0702 & - & 4691 & 4679 & 4667 & $4.6775 e+03$ & 6.6006 & - \\
\hline GWO & 2306 & 2297 & 2291 & $2.2967 \mathrm{e}+03$ & 4.3482 & - & 4686 & 4668 & 4657 & $4.6677 \mathrm{e}+03$ & 7.8227 & - \\
\hline HS & 2311 & 2302 & 2292 & $2.3014 \mathrm{e}+03$ & 4.1745 & - & 4698 & 4678 & 4665 & $4.6757 \mathrm{e}+03$ & 8.1110 & - \\
\hline PSO & 2312 & 2301 & 2292 & $2.3015 \mathrm{e}+0$. & 4.5314 & - & 4692 & 4675 & 4666 & $4.6765 \mathrm{e}+03$ & 7.1570 & - \\
\hline TLBO & 2312 & 2302 & 2293 & $2.3025 \mathrm{e}+03$ & 5.2572 & - & 4692 & 4672 & 4663 & $4.6741 \mathrm{e}+03$ & 7.5263 & - \\
\hline SGO & 2322 & 2312 & 2312 & $2.3147 e+03$ & 7.7901 & & 4739 & 4712 & 4689 & $4.7120 \mathrm{e}+03$ & 13.1293 & \\
\hline FPA & 2312 & 2301 & 2295 & $2.3019 \mathrm{e}+03$ & 4.3419 & - & 4690 & 4675 & 4668 & $4.6754 \mathrm{e}+03$ & 6.0440 & - \\
\hline FFA & 2322 & 2312 & 2311 & $2.3134 \mathrm{e}+03$ & 3.0240 & - & 4709 & 4698 & 4689 & $4.6977 \mathrm{e}+03$ & 5.0945 & - \\
\hline \multirow[t]{2}{*}{ Algorithm } & \multicolumn{6}{|c|}{ SCdata $3, \operatorname{dim}=300$} & \multicolumn{6}{|c|}{ SCdata $4, \operatorname{dim}=500$} \\
\hline & Best & Median & Worse & Mean & Std & WRS & Best & Median & Worse & Mean & Std & WRS \\
\hline $\mathrm{ABC}$ & 6883 & 6854 & 6830 & $6.8552 \mathrm{e}+03$ & 15.0594 & - & 10878 & 10461 & 10298 & $1.0502 \mathrm{e}+04$ & 169.5156 & - \\
\hline BA & 6873 & 6853 & 6834 & $6.8516 \mathrm{e}+03$ & 11.8778 & - & 11223 & 11159 & 11016 & $1.1147 \mathrm{e}+04$ & 44.5827 & - \\
\hline $\mathrm{BH}$ & 6855 & 6820 & 6799 & $6.8217 \mathrm{e}+03$ & 15.6539 & - & 11124 & 10951 & 10806 & $1.0947 \mathrm{e}+04$ & 83.8600 & - \\
\hline $\mathrm{CS}$ & 6871 & 6852 & 6838 & $6.8521 \mathrm{e}+03$ & 8.6969 & - & 11217 & 11129 & 11058 & $1.1132 \mathrm{e}+04$ & 39.1228 & - \\
\hline DE & 6884 & 6843 & 6823 & $6.8445 \mathrm{e}+03$ & 13.4901 & - & 11199 & 11079 & 10974 & $1.1080 \mathrm{e}+04$ & 61.9108 & - \\
\hline GWO & 6874 & 6829 & 6800 & $6.8326 \mathrm{e}+03$ & 17.4701 & - & 11159 & 10972 & 10888 & $1.0987 \mathrm{e}+04$ & 64.6446 & - \\
\hline HS & 6890 & 6841 & 6830 & $6.8432 \mathrm{e}+03$ & 12.9473 & - & 11206 & 11084 & 10966 & $1.1080 \mathrm{e}+04$ & 62.3268 & - \\
\hline PSO & 6882 & 6844 & 6826 & $6.8462 \mathrm{e}+03$ & 12.4155 & - & 11232 & 11155 & 10988 & $1.1142 \mathrm{e}+04$ & 57.3774 & - \\
\hline TLBO & 6881 & 6840 & 6817 & $6.8428 \mathrm{e}+03$ & 17.0241 & - & 11162 & 11063 & 10964 & $1.1068 \mathrm{e}+04$ & 57.6314 & - \\
\hline SGO & 6958 & 6930 & 6872 & $6.9262 \mathrm{e}+03$ & 21.5488 & & 11408 & 11347 & 11263 & $1.1339 e+04$ & 39.3516 & \\
\hline FPA & 6869 & 6838 & 6822 & 6840 & 11.9827 & - & 11238 & 11053 & 10970 & $1.1068 \mathrm{e}+04$ & 80.0177 & - \\
\hline FFA & 6892 & 6882 & 6869 & $6.8814 \mathrm{e}+03$ & 6.3706 & - & 11228 & 11199 & 11181 & $1.1199 \mathrm{e}+04$ & 11.6305 & - \\
\hline \multirow[t]{2}{*}{ Algorithm } & \multicolumn{6}{|c|}{ SCdata $5, \operatorname{dim}=700$} & & & SCdat & ta6, $\operatorname{dim}=1000$ & & \\
\hline & Best & Median & Worse & Mean & Std & WRS & Best & Median & Worse & Mean & Std & $\overline{\text { WRS }}$ \\
\hline $\mathrm{ABC}$ & 14099 & 13640 & 13389 & $1.3675 \mathrm{e}+04$ & 200.4054 & - & 19031 & 18520 & 18348 & $1.8594 \mathrm{e}+04$ & 216.3066 & - \\
\hline BA & 15579 & 15229 & 15100 & $1.5269 \mathrm{e}+04$ & 136.3518 & - & 21918 & 21647 & 21477 & $2.1656 e+04$ & 122.4750 & - \\
\hline $\mathrm{BH}$ & 15218 & 14944 & 14752 & $1.4942 \mathrm{e}+04$ & 102.2942 & - & 21539 & 21250 & 21048 & $2.1256 \mathrm{e}+04$ & 130.7398 & - \\
\hline $\mathrm{CS}$ & 15353 & 15157 & 15037 & $1.5171 \mathrm{e}+04$ & 79.7179 & - & 22056 & 21545 & 21377 & $2.1580 \mathrm{e}+04$ & 137.6301 & - \\
\hline $\mathrm{DE}$ & 15498 & 15121 & 14999 & $1.5147 \mathrm{e}+04$ & 128.9765 & - & 21752 & 21488 & 21352 & $2.1503 e+04$ & 105.7471 & - \\
\hline GWO & 15306 & 14970 & 14860 & $1.5011 \mathrm{e}+04$ & 115.5403 & - & 21633 & 21301 & 21170 & $2.1334 \mathrm{e}+04$ & 138.0600 & - \\
\hline HS & 15349 & 15078 & 14951 & $1.5095 \mathrm{e}+04$ & 106.3415 & - & 21672 & 21390 & 21239 & $2.1404 \mathrm{e}+04$ & 110.8265 & - \\
\hline PSO & 15566 & 15358 & 15036 & $1.5344 \mathrm{e}+04$ & 146.2778 & - & 22441 & 22024 & 21618 & $2.2008 \mathrm{e}+04$ & 202.2212 & - \\
\hline TLBO & 15386 & 15130 & 14999 & $1.5154 \mathrm{e}+04$ & 119.1638 & - & 21779 & 21539 & 21352 & $2.1522 \mathrm{e}+04$ & 106.0562 & - \\
\hline SGO & 15829 & 15770 & 15665 & $1.5764 \mathrm{e}+04$ & 42.8715 & & 22845 & 22769 & 22651 & $2.2760 e+04$ & 46.7444 & \\
\hline FPA & 15502 & 15093 & 14978 & $1.5118 \mathrm{e}+04$ & 111.4555 & - & 21792 & 21398 & 21197 & $2.1406 \mathrm{e}+04$ & 130.1908 & - \\
\hline FFA & 15610 & 15454 & 15370 & $1.5461 \mathrm{e}+04$ & 65.7216 & - & 22260 & 21941 & 21807 & $2.1974 \mathrm{e}+04$ & 125.0034 & - \\
\hline Algorithm & & & SCdate & $\mathrm{a}, \mathrm{dim}=1500$ & & & & & SCdat & ta8, $\operatorname{dim}=2000$ & & \\
\hline & Best & Median & Worse & Mean & Std & WRS & Best & Median & Worse & Mean & Std & WRS \\
\hline$\overline{\mathrm{ABC}}$ & 26778 & 26351 & 26044 & $2.6325 \mathrm{e}+04$ & 202.0349 & - & 35333 & 34171 & 33673 & $3.4237 \mathrm{e}+04$ & 444.9424 & - \\
\hline BA & 32247 & 31867 & 31574 & $3.1864 \mathrm{e}+04$ & 181.1630 & - & 43100 & 42295 & 42043 & $4.2360 \mathrm{e}+04$ & 234.0165 & - \\
\hline $\mathrm{BH}$ & 31978 & 31433 & 31185 & $3.1416 \mathrm{e}+04$ & 177.5944 & - & 42248 & 41653 & 41420 & $4.1692 \mathrm{e}+04$ & 205.1012 & - \\
\hline $\mathrm{CS}$ & 32292 & 31770 & 31582 & $3.1806 \mathrm{e}+04$ & 153.0968 & - & 42479 & 42128 & 41873 & $4.2119 \mathrm{e}+04$ & 156.2905 & - \\
\hline DE & 31986 & 31660 & 31427 & $3.1666 \mathrm{e}+04$ & 146.1943 & - & 42485 & 42028 & 41774 & $4.2028 \mathrm{e}+04$ & 164.2030 & - \\
\hline GWO & 31818 & 31491 & 31318 & $3.1497 \mathrm{e}+04$ & 138.0504 & - & 42292 & 41738 & 41524 & $4.1782 \mathrm{e}+04$ & 190.6987 & - \\
\hline HS & 31889 & 31668 & 31440 & $3.1661 \mathrm{e}+04$ & 130.8470 & - & 42229 & 41846 & 41621 & $4.1851 \mathrm{e}+04$ & 156.3408 & - \\
\hline PSO & 33260 & 32720 & 31844 & $3.2627 \mathrm{e}+04$ & 344.6677 & - & 44363 & 43403 & 42864 & $4.3426 \mathrm{e}+04$ & 346.4391 & - \\
\hline TLBO & 32345 & 31722 & 31575 & $3.1775 \mathrm{e}+04$ & 165.7838 & - & 42566 & 42049 & 41809 & $4.2059 \mathrm{e}+04$ & 179.2287 & - \\
\hline SGO & 34290 & 34162 & 33880 & $3.4143 \mathrm{e}+04$ & 101.0356 & & 45848 & 45714 & 45605 & $4.5724 \mathrm{e}+04$ & 59.3497 & \\
\hline FPA & 31843 & 31525 & 31407 & $3.1583 \mathrm{e}+04$ & 127.5541 & - & 42347 & 41875 & 41639 & $4.1907 \mathrm{e}+04$ & 190.5675 & - \\
\hline FFA & 32504 & 32236 & 32090 & $3.2240 \mathrm{e}+04$ & 116.3916 & - & 42967 & 42588 & 42376 & $4.2580 \mathrm{e}+04$ & 141.8856 & - \\
\hline Algorithm & & & SCdate & $a 9, \operatorname{dim}=3000$ & & & & & SCdate & $\mathrm{a} 10, \operatorname{dim}=5000$ & & \\
\hline & Best & Median & Worse & Mean & Std & WRS & Best & Median & Worse & Mean & Std & WRS \\
\hline $\mathrm{ABC}$ & 50291 & 49947 & 49761 & $4.9985 \mathrm{e}+04$ & 202.3667 & - & 80331 & 79960 & 79812 & 80003 & 198.0088 & - \\
\hline BA & 63515 & 62663 & 62501 & $6.2788 \mathrm{e}+04$ & 416.9601 & - & 104363 & 104033 & 103500 & 103925 & 341.7287 & - \\
\hline $\mathrm{BH}$ & 62159 & 61320 & 61143 & $6.1490 \mathrm{e}+04$ & 400.1497 & - & 101830 & 101778 & 101388 & $1.0165 \mathrm{e}+05$ & 202.1702 & - \\
\hline $\mathrm{CS}$ & 62340 & 62100 & 62067 & 62163 & 122.2845 & - & 102929 & 102368 & 102291 & $1.0248 \mathrm{e}+05$ & 259.6812 & - \\
\hline $\mathrm{DE}$ & 62379 & 62168 & 62010 & $6.2195 \mathrm{e}+04$ & 157.7317 & - & 102215 & 101956 & 101892 & $1.0199 \mathrm{e}+05$ & 129.6430 & - \\
\hline GWO & 61982 & 61815 & 61731 & $6.1830 \mathrm{e}+04$ & 92.7723 & - & 102927 & 102157 & 101976 & $1.0230 \mathrm{e}+05$ & 392.0825 & - \\
\hline HS & 62050 & 61717 & 61583 & $6.1782 \mathrm{e}+04$ & 178.9897 & - & 102316 & 102254 & 101778 & $1.0213 e+05$ & 224.2124 & - \\
\hline PSO & 65135 & 64667 & 64530 & $6.4750 \mathrm{e}+04$ & 239.7430 & - & 107616 & 107333 & 106772 & $1.0726 \mathrm{e}+05$ & 374.9071 & - \\
\hline TLBO & 62274 & 62107 & 61990 & $6.2116 \mathrm{e}+04$ & 109.5276 & - & 102614 & 102480 & 102442 & 102500 & 68.2971 & - \\
\hline SGO & 68479 & 68382 & 68211 & $6.8363 \mathrm{e}+04$ & 115.0270 & & 114431 & 114315 & 114295 & $1.1433 e+05$ & 55.7611 & \\
\hline FPA & 62067 & 61940 & 61784 & $6.1921 \mathrm{e}+04$ & 113.6561 & - & 102719 & 102122 & 101992 & $1.0231 \mathrm{e}+05$ & 342.3663 & - \\
\hline FFA & 63515 & 62663 & 62067 & $6.2388 \mathrm{e}+04$ & 416.9601 & - & 104363 & 104033 & 103500 & 103925 & 123.7812 & - \\
\hline
\end{tabular}
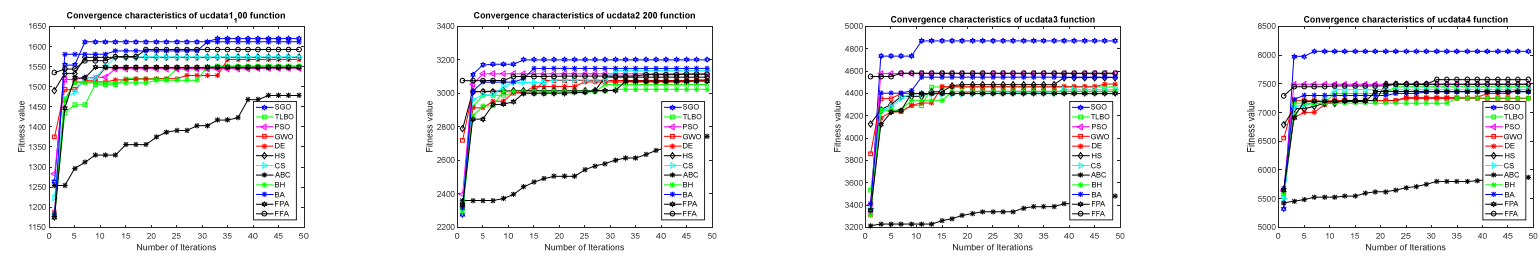

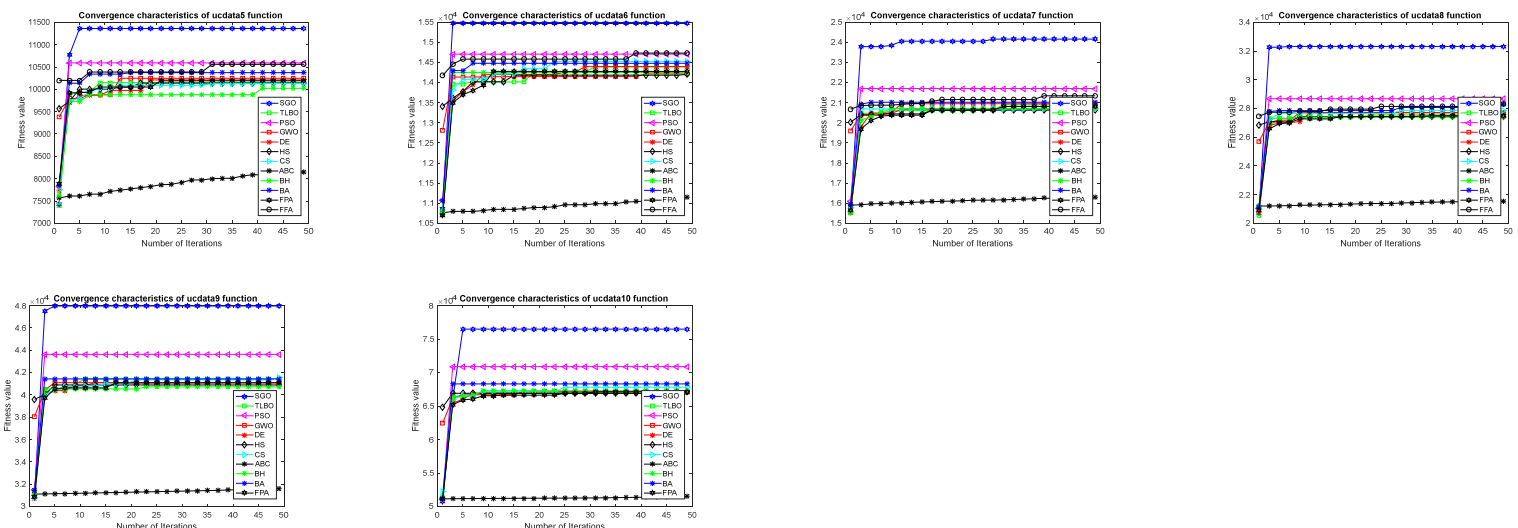

Fig. 3. Convergence characteristics of uncorrelated 0-1 KPs on first 50 iterations
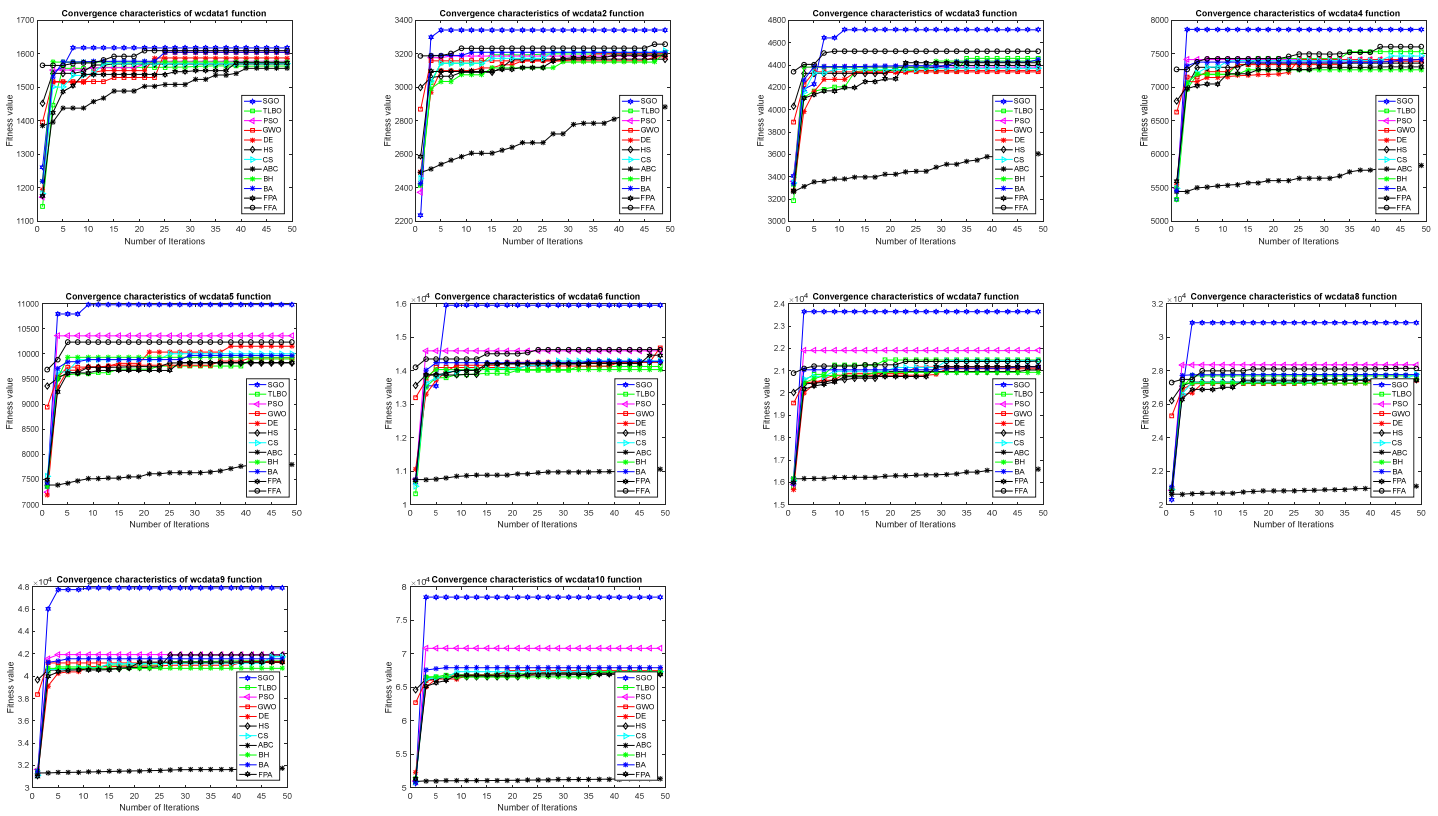

Fig. 4. Convergence characteristics of weakly correlated 0-1 KPs on first 50 iterations


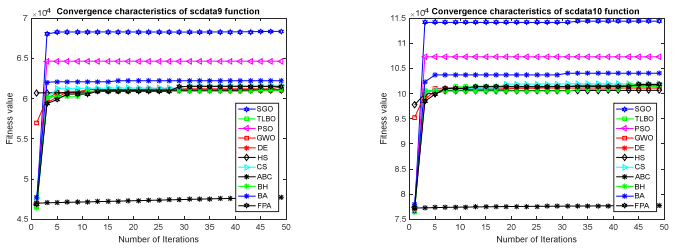

Fig. 5. Convergence characteristics of strongly correlated 0-1 KPs on first 50 iterations

\section{Performance estimation}

The performance of the proposed BSGO algorithm is investigated by using the Wilcoxon rank-sum (WRS) test for a better comparison. WRS test is a nonparametric test that utilized in a hypothesis testing situation involving a design with two samples (Derrac et al., 2011). It is a pair-wise test that aims to find out significant differences between the behaviors of two algorithms. Therefore, we have conducted the WRS test at 0.05 significance level on experimental results for proposed BSGO algorithm against the different algorithm appears in Table 4, Table 5 and Table 6 and the obtained results are reported in the last column of the same table.

\section{Discussion}

From Table 4, Table 5, Table 6, according to the WRS test it clearly indicates that the proposed BSGO algorithm achieves better results than all other algorithms for all 30 large-scale 0-1 KPs. From graphs, it is clearly visible that the proposed BSGO achieves better simulation results than all different algorithms within ten iterations itself. Consequently, the profit for each problem has improved significantly by BSGO. So it can be concluded that the proposed BSGO has some excellent characteristics of better optimization ability and good convergence as well. BSGO is a promising variant of SGO and has a strong ability to solve large-scale $0-1 \mathrm{KP}$ problems than other investigated algorithms.

\section{Conclusions and future work}

This paper presented a novel binary social group optimization algorithm (BSGO) for solving 0/1 knapsack problems. The proposed algorithm has been extensively investigated through using 10 small-scale and 30 large-scale problems of $0-1 \mathrm{KP}$. The proposed algorithm is compared with several algorithms from the literature. Based on statistical measures, the proposed algorithm can explore better-quality solutions, and it outperforms than other compared algorithms, especially in large-scale 0-1 KPs, and comes out as one of the best algorithm. From convergence graphs, it is clearly visible that within ten iterations itself BSGO algorithm finds better results than other algorithms. The results reveal that BSGO is competent to provide very competitive results compared to other investigated algorithms. For future work, it is possible to investigate the proposed BSGO algorithm to solve different forms of KP problems like multi-dimensional KP and quadratic KP as well as various combinatorial optimization problems such as subset sum problem, quadratic assignment problem, and job shop scheduling problems.

\section{Compliance with ethical standards}

Conflict of Interest: The authors declare that they have no conflict of interest.

\section{References}

Abdel-Basset, M., El-Shahat, D., \& El-Henawy, I. (2019). Solving 0-1 knapsack problem by binary flower pollination algorithm. Neural Computing and Applications, 31(9), 5477-5495.

Abdel-Basset, M., Luo, Q., Miao, F., \& Zhou, Y. (2017). Solving 0-1 knapsack problems by binary dragonfly algorithm. In International conference on intelligent computing (pp. 491-502). Springer, Cham.

Abdel-Basset, M., \& Zhou, Y. (2018). An elite opposition-flower pollination algorithm for a 0-1 knapsack problem. International Journal of Bio-Inspired Computation, 11(1), 46-53.

Bansal, J. C., \& Deep, K. (2012). A modified binary particle swarm optimization for knapsack problems. Applied Mathematics and Computation, 218(22), 11042-11061.

Bhattacharjee, K. K., \& Sarmah, S. P. (2014). Shuffled frog leaping algorithm and its application to 0/1 knapsack problem. Applied Soft Computing, 19, 252-263.

Catharin, A. R., Kumar, A. S., Rakshiga, M., Kumaresan, S., \& Raja, N. S. M. (2018, March). Examination of Glioblastoma Images by Thresholding using Heuristic Approach. In 2018 Fourth International Conference on Biosignals, Images and Instrumentation (ICBSII) (pp. 206-212). IEEE. 
Chakravarthy, V. S., Chowdary, P. S. R., Satpathy, S. C., Terlapu, S. K., \& Anguera, J. (2018). Antenna array synthesis using social group optimization. In Microelectronics, Electromagnetics and Telecommunications (pp. 895-905). Springer, Singapore.

Changdar, C., Mahapatra, G. S., \& Pal, R. K. (2013). An ant colony optimization approach for binary knapsack problem under fuzziness. Applied Mathematics and Computation, 223, 243-253.

Cobos, C., Dulcey, H., Ortega, J., Mendoza, M., \& Ordoñez, A. A Binary Fisherman Search Procedure for the 0/1 Knapsack Problem. Advances in Artificial Intelligence: Proceedings of the 17th Conference of the Spanish Association for Artificial Intelligence, CAEPIA 2016. O. Luaces et al.

Derrac, J., García, S., Molina, D., \& Herrera, F. (2011). A practical tutorial on the use of nonparametric statistical tests as a methodology for comparing evolutionary and swarm intelligence algorithms. Swarm and Evolutionary Computation, 1(1), 3-18.

Dey, N., Rajinikanth, V., Ashour, A. S., \& Tavares, J. M. R. (2018). Social group optimization supported segmentation and evaluation of skin melanoma images. Symmetry, 10(2), 51.

Du, D. P., \& Zu, Y. R. (2015). Greedy strategy based self-adaption ant colony algorithm for 0/1 knapsack problem. In Ubiquitous Computing Application and Wireless Sensor (pp. 663-670). Springer, Dordrecht.

Fang, J., Zheng, H., Liu, J., Zhao, J., Zhang, Y., \& Wang, K. (2018). A transformer fault diagnosis model using an optimal hybrid dissolved gas analysis features subset with improved social group optimization-support vector machine classifier. Energies, 11(8), 1922.

Feng, Y., Wang, G. G., Feng, Q., \& Zhao, X. J. (2014). An effective hybrid cuckoo search algorithm with improved shuffled frog leaping algorithm for 0-1 knapsack problems. Computational Intelligence and Neuroscience, 2014.

Feng, Y., Wang, G. G., Dong, J., \& Wang, L. (2018). Opposition-based learning monarch butterfly optimization with Gaussian perturbation for large-scale 0-1 knapsack problem. Computers \& Electrical Engineering, 67, 454-468.

Feng, Y., Wang, G. G., Deb, S., Lu, M., \& Zhao, X. J. (2017). Solving 0-1 knapsack problem by a novel binary monarch butterfly optimization. Neural Computing and Applications, 28(7), 1619-1634.

Gherboudj, A., Layeb, A., \& Chikhi, S. (2012). Solving 0-1 knapsack problems by a discrete binary version of cuckoo search algorithm. International Journal of Bio-Inspired Computation, 4(4), 229-236.

Gong, Q. Q., Zhou, Y. Q., \& Yang, Y. (2011). Artificial glowworm swarm optimization algorithm for solving 0-1 knapsack problem. In Advanced materials research (Vol. 143, pp. 166-171). Trans Tech Publications Ltd.

Kong, M., \& Tian, P. (2006, June). Apply the particle swarm optimization to the multidimensional knapsack problem. In International conference on artificial intelligence and soft computing (pp. 1140-1149). Springer, Berlin, Heidelberg.

Kong, X., Gao, L., Ouyang, H., \& Li, S. (2015). A simplified binary harmony search algorithm for large scale 0-1 knapsack problems. Expert Systems with Applications, 42(12), 5337-5355.

Kulkarni, A. J., Krishnasamy, G., \& Abraham, A. (2017). Solution to 0-1 knapsack problem using cohort intelligence algorithm. In Cohort Intelligence: A Socio-inspired Optimization Method (pp. 55-74). Springer, Cham.

Layeb, A. (2011). A novel quantum inspired cuckoo search for knapsack problems. International Journal of Bio-inspired Computation, 3(5), 297-305.

Leena, J. G., Sundaravadivu, K., Monisha, R., \& Rajinikanth, V. (2018, July). Design of Fractional-Order PI/PID Controller for SISO System Using Social-Group-Optimization. In 2018 IEEE International Conference on System, Computation, Automation and Networking (ICSCA) (pp. 1-5). IEEE.

Lim, T. Y., Al-Betar, M. A., \& Khader, A. T. (2016). Taming the 0/1 knapsack problem with monogamous pairs genetic algorithm. Expert Systems with Applications, 54, 241-250.

Lin, C. J., Chern, M. S., \& Chih, M. (2016). A binary particle swarm optimization based on the surrogate information with proportional acceleration coefficients for the 0-1 multidimensional knapsack problem. Journal of Industrial and Production Engineering, 33(2), 77-102.

Lv, J., Wang, X., Huang, M., Cheng, H., \& Li, F. (2016). Solving 0-1 knapsack problem by greedy degree and expectation efficiency. Applied Soft Computing, 41, 94-103.

Ma, Y., \& Wan, J. (2011, July). Improved hybrid adaptive genetic algorithm for solving knapsack problem. In $20112 n d$ International Conference on Intelligent Control and Information Processing (Vol. 2, pp. 644-647). IEEE.

Madhavi, G., \& Harika, V. (2018). Implementation of social group optimization to economic load dispatch problem. International Journal of Applied Engineering Research, 13(13), 11195-11200.

Mani, M. S., Manisha, S., Thanaraj, K. P., \& Rajinikanth, V. (2017, July). Automated segmentation of Giemsa stained microscopic images based on entropy value. In 2017 International Conference on Intelligent Computing, Instrumentation and Control Technologies (ICICICT) (pp. 1124-1128). IEEE.

Martello, S., Pisinger, D., \& Toth, P. (2000). New trends in exact algorithms for the 0-1 knapsack problem. European Journal of Operational Research, 123(2), 325-332.

Monisha, R., Mrinalini, R., Britto, M. N., Ramakrishnan, R., \& Rajinikanth, V. (2019). Social group optimization and Shannon's function-based RGB image multi-level thresholding. In Smart Intelligent Computing and Applications (pp. 123-132). Springer, Singapore.

Naik, A., \& Satapathy, S. C. (2021). A comparative study of social group optimization with a few recent optimization algorithms. Complex \& Intelligent Systems, 7(1), 249-295.

Naik, A., Satapathy, S. C., \& Abraham, A. (2020). Modified Social Group Optimization-A meta-heuristic algorithm to solve short-term hydrothermal scheduling. Applied Soft Computing, 95, 106524. 
Naik, A., Satapathy, S. C., Ashour, A. S., \& Dey, N. (2018). Social group optimization for global optimization of multimodal functions and data clustering problems. Neural Computing and Applications, 30(1), 271-287.

Naik, A., Satapathy, S. C., \& Jena, J. J. (2021). Non-dominated Sorting Social Group Optimization algorithm for multiobjective optimization. Journal of Scientific and Industrial Research (JSIR), 80(02), 129-136.

Nguyen, P. H., Wang, D., \& Truong, T. K. (2017). A novel binary social spider algorithm for 0-1 knapsack problem. Internatioanl Journal of Innovative Computation Information Control, 13(6), 2039-2049.

Nguyen, P. H., Wang, D., \& Truong, T. K. (2016). A new hybrid particle swarm optimization and greedy for 0-1 knapsack problem. Indonesian Journal of Electronic Engeering Compututation Science, 1(3), 411-418.

Parwekar, P. (2020). SGO a new approach for energy efficient clustering in WSN. In Sensor Technology: Concepts, Methodologies, Tools, and Applications (pp. 716-734). IGI Global.

Pavithr, R. S. (2016). Quantum Inspired Social Evolution (QSE) algorithm for 0-1 knapsack problem. Swarm and Evolutionary Computation, 29, 33-46.

Pham, A. H., Vu, T. V., \& Tran, T. M. (2017, August). Optimal Volume Fraction of Functionally Graded Beams with Various Shear Deformation Theories Using Social Group Optimization. In International Conference on Advances in Computational Mechanics (pp. 395-408). Springer, Singapore.

Praveen, S. P., Rao, K. T., \& Janakiramaiah, B. (2018). Effective allocation of resources and task scheduling in cloud environment using social group optimization. Arabian Journal for Science and Engineering, 43(8), 4265-4272.

Rajinikanth, V., \& Satapathy, S. C. (2018). Segmentation of ischemic stroke lesion in brain MRI based on social group optimization and Fuzzy-Tsallis entropy. Arabian Journal for Science and Engineering, 43(8), 4365-4378.

Rani, S., \& Suri, B. (2019, July). Adopting social group optimization algorithm using mutation testing for test suite generation: SGO-MT. In International Conference on Computational Science and Its Applications (pp. 520-528). Springer, Cham.

Razavi, S. F., \& Sajedi, H. (2015). Cognitive discrete gravitational search algorithm for solving 0-1 knapsack problem. Journal of Intelligent \& Fuzzy Systems, 29(5), 2247-2258.

Rizk-Allah, R. M., \& Hassanien, A. E. (2018). New binary bat algorithm for solving 0-1 knapsack problem. Complex \& Intelligent Systems, 4(1), 31-53.

Satapathy, S., \& Naik, A. (2016). Social group optimization (SGO): a new population evolutionary optimization technique. Complex \& Intelligent Systems, 2(3), 173-203.

Shi, H. (2006, August). Solution to 0/1 knapsack problem based on improved ant colony algorithm. In 2006 IEEE International Conference on Information Acquisition (pp. 1062-1066). IEEE.

Sonuc, E., Sen, B., \& Bayir, S. (2016). A parallel approach for solving 0/1 knapsack problem using simulated annealing algorithm on CUDA platform. International Journal of Computer Science and Information Security, 14(12), 1096.

Tran, M. T., Pham, H. A., Nguyen, V. L., \& Trinh, A. T. (2017). Optimisation of stiffeners for maximum fundamental frequency of cross-ply laminated cylindrical panels using social group optimisation and smeared stiffener method. ThinWalled Structures, 120, 172-179.

Truong, T. K., Li, K., Xu, Y., Ouyang, A., \& Nguyen, T. T. (2015). Solving 0-1 knapsack problem by artificial chemical reaction optimization algorithm with a greedy strategy. Journal of Intelligent \& Fuzzy Systems, 28(5), $2179-2186$.

Ulker, E., \& Tongur, V. (2017). Migrating birds optimization (MBO) algorithm to solve knapsack problem. Procedia Computer Science, 111, 71-76.

Wang, L., Yang, R., Xu, Y., Niu, Q., Pardalos, P. M., \& Fei, M. (2013). An improved adaptive binary harmony search algorithm. Information Sciences, 232, 58-87.

Yan, C., Gao, S., Luo, H., \& Hu, Z. (2015, June). A hybrid algorithm based on tabu search and chemical reaction optimization for 0-1 knapsack problem. In International Conference in Swarm Intelligence (pp. 229-237). Springer, Cham.

Zhang, X., Huang, S., Hu, Y., Zhang, Y., Mahadevan, S., \& Deng, Y. (2013). Solving 0-1 knapsack problems based on amoeboid organism algorithm. Applied Mathematics and Computation, 219(19), 9959-9970.

Zhou, G., Zhao, R., \& Zhou, Y. (2018). Solving large-scale 0-1 knapsack problem by the social-spider optimisation algorithm. International Journal of Computing Science and Mathematics, 9(5), 433-441.

Zhou, Y., Bao, Z., Luo, Q., \& Zhang, S. (2017). A complex-valued encoding wind driven optimization for the 0-1 knapsack problem. Applied Intelligence, 46(3), 684-702.

Zhou, Y., Chen, X., \& Zhou, G. (2016). An improved monkey algorithm for a 0-1 knapsack problem. Applied Soft Computing, 38, 817-830.

Zhou, Y., Li, L., \& Ma, M. (2016). A complex-valued encoding bat algorithm for solving 0-1 knapsack problem. Neural Processing Letters, 44(2), 407-430.

Zou, D., Gao, L., Li, S., \& Wu, J. (2011). Solving 0-1 knapsack problem by a novel global harmony search algorithm. Applied Soft Computing, 11(2), 1556-1564. 
Appendix A

Table A1.

List of small-scale 0-1 knapsack problems

\begin{tabular}{ccccc}
\hline $\begin{array}{c}\text { Problem } \\
\text { No. }\end{array}$ & Dimension & Capacity & Weights & Profits \\
\hline P1 & 10 & 269 & {$[95,4,60,32,23,72,80,62,65,46]$} & {$[55,10,47,5,4,50,8,61,85,87]$} \\
P2 & 20 & 878 & {$[92,4,43,83,84,68,92,82,6,44,32,18,56$,} & {$[44,46,90,72,91,40,75,35,8,54,78,40,77,15$,} \\
& & & $83,25,96,70,48,14,58]$ & $61,17,75,29,75,63]$ \\
P3 & 4 & 20 & {$[6,5,9,7]$} & {$[9,11,13,15]$} \\
P4 & 4 & 11 & {$[2,4,6,7]$} & {$[6,10,12,13]$} \\
P5 & 15 & 375 & {$[56.358531,80.874050,47.987304,89.596240$,} & {$[0.125126,19.330424,58.500931,35.029145$,} \\
& & & $74.660482,85.894345,51.353496,1.498459$, & $82.284005,17.410810,71.050142,30.399487$, \\
& & & $36.445204,16.589862,44.569231,0.466933$, & 9.140294, \\
& & & $37.788018,57.118442,60.716575]$ & $14.731285,98.852504,11.908322,0.891140$, \\
P6 & 10 & 60 & {$[30,25,20,18,17,11,5,2,1,1]$} & $53.166295,60.176397]$ \\
P7 & 7 & 50 & {$[31,10,20,19,4,3,6]$} & {$[20,18,17,15,15,10,5,3,1,1]$} \\
P8 & 23 & 10000 & {$[983,982,981,980,979,978,488,976,972$,} & {$[981,980,979,978,977,976,487,974,970,485$,} \\
& & & $486,486,972,972,485,485,969,966,483,964$, & $485,970,970,484,484,976,974,482,962,961,959$, \\
& & & $963,961,958,959]$ & $958,857]$ \\
P9 & 5 & 80 & {$[15,20,17,8,31]$} & {$[33,24,36,37,12]$} \\
P10 & 20 & 879 & {$[84,83,43,4,44,6,82,92,25,83,56,18,58$,} & {$[91,72,90,46,55,8,35,75,61,15,77,40,63,75$,} \\
& & & $14,48,70,96,32,68,92]$ & $29,75,17,78,40,44]$ \\
\hline
\end{tabular}

Table A2.

Correlation characteristics of profit and weight for large-scale 0-1 knapsack problem

\begin{tabular}{cccc}
\hline Correlation & Weight $\left(\boldsymbol{w}_{\boldsymbol{i}}\right)$ & Profit $\left.\left(\boldsymbol{p}_{\boldsymbol{i}}\right)\right)$ & $\mathbf{C}$ \\
\hline Uncorrelated items & $\operatorname{Rand}(10,30)$ & $\operatorname{Rand}(10,30)$ & $0.75^{*} \sum_{i=1}^{N} w_{i}$ \\
Weakly correlated items & $\operatorname{Rand}(10,30)$ & $\operatorname{Rand}\left(w_{i}-10, w_{i}+10\right)$ & $0.75^{*} \sum_{i=1}^{N} w_{i}$ \\
Strongly correlated items & $\operatorname{Rand}(10,30)$ & $w_{i}+10$ & $0.75^{*} \sum_{i=1}^{N} w_{i}$ \\
\hline
\end{tabular}

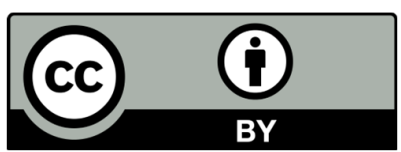

(C) 2022 by the authors; licensee Growing Science, Canada. This is an open access article distributed under the terms and conditions of the Creative Commons Attribution (CC-BY) license (http://creativecommons.org/licenses/by/4.0/). 